\title{
Acoustic Trauma Causes Cochlear Pericyte-to-Myofibroblast-Like Cell Transformation and Vascular Degeneration, and Transplantation of New Pericytes Prevents Vascular Atrophy
}

\author{
Zhiqiang Hou, ${ }^{*}$ Lingling Neng, ${ }^{*}$ Jinhui Zhang, ${ }^{*}$ Jing Cai, ${ }^{*}$ Xiaohan Wang, ${ }^{* \dagger}$ Yunpei Zhang, ${ }^{*}$ Ivan A. Lopez, ${ }^{\ddagger}$ and Xiaorui Shi ${ }^{\star}$
}

From the Department of Otolaryngology/Head \& Neck Surgery,* Oregon Hearing Research Center, Oregon Health \& Science University, Portland, Oregon; the Center for Life Sciences, Boston Children's Hospital, ${ }^{\dagger}$ Harvard Medical School, Boston, Massachusetts; and the Cellular and Molecular Biology of the Inner Ear Laboratory, ${ }^{\ddagger}$ Department of Head and Neck Surgery, David Geffen School of Medicine at UCLA, Los Angeles, California

\author{
Accepted for publication \\ May 26, 2020. \\ Address correspondence to \\ Xiaorui Shi, M.D., Ph.D., \\ Department of Otolaryngology, \\ Oregon Hearing Research \\ Center, Mail Code NRC04, \\ Oregon Health \& Science \\ University, 3181 S.W. Sam \\ Jackson Park Rd., Portland, OR \\ 97239. E-mail: shix@ohsu. \\ edu.
}

\begin{abstract}
Acoustic trauma disrupts cochlear blood flow and damages sensory hair cells. Damage and regression of capillaries after acoustic trauma have long been observed, but the underlying mechanism of pathology has not been understood. We show herein that loud sound causes change of phenotype from neural/glial antigen 2 positive/ $\alpha$-smooth muscle actin negative to neural/glial antigen 2 positive/ $\alpha$-smooth muscle actin positive in some pericytes $(\mathrm{PCS})$ on strial capillaries that is strongly associated with up-regulation of transforming growth factor- $\beta 1$. The acoustic trauma also reduced capillary density and increased deposition of matrix proteins, particularly in the vicinity of transformed PCs. In a newly established in vitro three-dimensional endothelial cell (EC) and PC co-culture model, transformed PCs induced thicker capillary-like branches in ECs and increased collagen IV and laminin expression. Transplantation of exogenous PCs derived from neonatal day 10 mouse cochleae to acoustic traumatized cochleae, however, significantly attenuated the decreased vascular density in the stria. Transplantation of PCs pretransfected with adeno-associated virus 1-vascular endothelial growth factor-A165 under control of a hypoxiaresponse element markedly promotes vascular volume and blood flow, increased proliferation of PCs and ECs, and attenuated loud sound-caused loss in endocochlear potential and hearing. Our results indicate that loud sound-triggered $\mathrm{PC}$ transformation contributes to capillary wall thickening and regression, and young $\mathrm{PC}$ transplantation effectively rehabilitates the vascular regression and improves hearing. (Am J Pathol 2020, 190: 1943-1959; https://doi.org/10.1016/j.ajpath.2020.05.019)
\end{abstract}

Noise-induced hearing loss has a profound impact on individuals, causing communication problems and social isolation. Noise not only damages auditory sensory cells, but also markedly affects the cochlear lateral wall and impairs the microvasculature in the stria. ${ }^{1-6}$ Although destructive changes in strial capillaries (vessel shutdown and intravascular strand formation) and strial regression following acoustic exposure have long been observed, ${ }^{1,3,7-11}$ the mechanism underlying the pathology remains largely unknown. In this study, we identify, for the first time, that acoustic trauma causes pericyte (PC)-to-myofibroblast-like cell [PC positive to $\alpha$-smooth muscle actin ( $\alpha$-SMA)] transformation and is one of the pathologies responsible for strial capillary atrophy.
Normal blood flow to the ear is critical for hearing acuity. $^{12,13}$ A remarkably intricate vascular system is deeply packed into the inner ear to provide timely supply of oxygen and nutrients to all cells in the ear. The most critical microvascular bed, formed by thin endothelial tubes lined with a rich population of PCs, is located in the stria of the

Supported by NIH/National Institute on Deafness and Other Communication Disorders (NIDCD) grants R21 DC016157 (X.S.), NIH/NIDCD R01 DC015781 (X.S.), NIH/NIDCD R01-DC010844 (X.S.), NIH P30DC005983, and Oregon Health \& Science University Medical Research Foundation (X.S.).

Z.H. and L.N. contributed equally to this work.

Disclosures: None declared. 
cochlear lateral wall. ${ }^{13,14}$ This vascular bed receives the larger portion of cochlear blood flow, and is essential for cochlear homeostasis and extremely important for generating the endocochlear potential (EP) on which sound transduction by hair cells depends. PCs, specialized mural cells, are located on the abluminal surface of microvessels. They interact with the endothelium, and are vital for vascular development, blood flow regulation, vascular integrity, and tissue fibrogenesis. ${ }^{15-19}$ In contrast, PC pathology leads to vascular dysfunction, seen in many different pathologic conditions, such as brain stroke, heart infarct, retinal disease, ${ }^{20-24}$ and diabetic retinopathy. ${ }^{25,26}$

The PC-to-myofibroblast transition was first reported in the central nervous system in wound formation following spinal cord injury. ${ }^{27}$ Subsequently, the PC-to-myofibroblast transition has been shown in skin, skeletal muscle, lung, intestine, and kidney. ${ }^{28-30}$ The myofibroblast is a specialized cell type that synthesizes collagen and other extracellular matrix components. ${ }^{16}$ The excessive deposition of extracellular matrix components produced by myofibroblasts transformed from PCs leads to tissue fibrosis and capillary degeneration. ${ }^{28,31,32}$ The PC-to-myofibroblast transition in other organs strongly involves transforming growth factor (TGF)- $\beta 1$ signaling. ${ }^{32-34}$ TGF- $\beta 1$, a pluripotent growth factor that regulates cell proliferation and differentiation, is a major signal in PC-induced tissue fibrogenesis. ${ }^{20,34-36}$ In this study, we found the cochlear PC transition also highly associated with TGF- $\beta 1$ signaling, and strongly supported by our results in both the in vivo loud sound trauma animal model and in vitro cell line-based model. Blockage of the TGF- $\beta 1$ signal significantly attenuates the PC-to-myofibroblast transformation in the cochlea.

Vascular remodeling and repair after damage are critical for restoration of normal vascular function. In the inner ear, normal blood supply is particularly critical for maintaining the EP, ion transport, and fluid balance. ${ }^{37-40}$ To sustain hearing acuity, a healthy cochlear microenvironment must be maintained. This is particularly true because generation of the EP, an essential driving force for hair cell sound transduction, is so metabolically demanding. ${ }^{40}$

PCs retain mesenchymal stem cell properties that have been shown to play a key role in wound healing, particularly in vascular repair and regeneration. ${ }^{41}$ Recently, therapeutic targeting of PCs has begun to be considered as a novel clinical treatment. ${ }^{20,42,43}$ PCs activate the angiogenic process by releasing various growth factors, such as basic fibroblast growth factor, hepatocyte growth factor, epidermal growth factor, and angiopoietin, to induce endothelial cell (EC) proliferation. ${ }^{42,44}$ In this study, we ask a fundamental question: Can transplantation of PCs restore damaged strial vasculature in the inner ear? To answer this question, PC capability was tested in an in vitro cell line-based three-dimensional coculture model, which showed that cochlear PCs dramatically promote sprouting angiogenesis. In further study, transplantation of fresh cochlear PCs derived from neonatal day 10 mouse cochleae (neo-PCs) to animals 2 weeks after loud sound trauma significantly increased vascular volume and boosted cochlear blood flow. We observed that transplantation of neoPCs to damaged cochlea not only facilitates restoration of vascular function, but also improves EP and hearing sensitivity. Taken together, our data show that cochlear PCs, as multipotent progenitor cells, are key for vascular health in the inner ear. However, PCs were found to be a double-edged sword. On the one hand, the PC phenotype conversion leads to capillary regression. On the other hand, transplantation of healthy PCs effectively rehabilitates the strial atrophy and other vascular defects following loud sound exposure.

\section{Materials and Methods}

\section{Animals}

Male C57BL/6J mice (aged approximately 6 weeks; stock number 000664) and NG2DsRedBAC transgenic mice (stock number 008241) were purchased from Jackson Laboratory (Bar Harbor, ME) and used in this study. NG2DsRedBAC transgenic mice were used for tracking the change of phenotype in the pericytes. These NG2DsRedBAC transgenic mice express an optimized red fluorescent protein variant (DsRed.T1) under the control of a mouse neural/glial antigen 2 (NG2) (Cspg4) promoter/enhancer. A colony was maintained at our animal care facility. For breeding, guidance from the Jackson Laboratory was followed. The NG2DsRedBAC transgenic mice were crossed with C57BL/6 wild-type mice for $>20$ generations. All procedures were reviewed and approved by the Institutional Animal Care and Use Committee at Oregon Health \& Science University (Institutional Animal Care and Use Committee approval number TR01_IP00000968).

\section{Noise Exposure}

Animals were placed in wire mesh cages and exposed to broadband noise at $120-\mathrm{dB}$ sound pressure level in a sound exposure booth for 3 hours and for an additional 3 hours the following day. The routinely used noise exposure regimen produces permanent loss of cochlear sensitivity. ${ }^{45}$

\section{Drug Treatment}

To determine whether TGF- $\beta 1$ signaling mediates transformation of strial PCs in the loud sound-stimulated condition, the TGF- $\beta 1$ signal was blocked with SB525334 (Selleckchem, Houston, TX), a potent blocker of the TGF- $\beta 1$ receptor. Specifically, NG2DsRedBAC transgenic mice were divided into two groups (six animals per group): noise exposed + saline and noise exposed + SB525334. For group 2, animals received SB525334 at $10 \mathrm{mg} / \mathrm{kg}$ per day ${ }^{46,47}$ in saline administered intraperitoneally immediately after loud sound stimulation for 1 or 2 weeks. Animals in the control group (group 1) received the same volume of 
Table 1 Antibodies Applied in the Study

\begin{tabular}{|c|c|c|c|c|c|}
\hline Antibodies & Vectors & Catalog no. & Dilution & Source & Specificity \\
\hline$\alpha-S M A^{21}$ & Abcam (Cambridge, MA) & ab5694 & $1: 100$ (with $1 \%$ BSA-PBS) & Rabbit & $\begin{array}{l}\text { Mouse, rat, } \\
\text { chicken, human }\end{array}$ \\
\hline$\alpha-S M A(W B)$ & Abcam & ab5694 & $1: 1000$ (with $5 \%$ skim milk) & Rabbit & $\begin{array}{l}\text { Mouse, rat, } \\
\text { chicken, human }\end{array}$ \\
\hline PDGFR $^{21}$ & Abcam & ab32570 & $1: 50$ (with $1 \%$ BSA-PBS) & Rabbit & Mouse, rat, human \\
\hline PDGFR $\beta^{21}$ & Abcam & ab69506 & $1: 50$ (with $1 \%$ BSA-PBS) & Mouse & Mouse, rat, human \\
\hline Collagen IV (WB) & Abcam & ab6586 & 1:1000 (with $5 \%$ skim milk) & Rabbit & $\begin{array}{l}\text { Mouse, rat, } \\
\text { hamster, human }\end{array}$ \\
\hline Collagen IV ${ }^{21}$ & Abcam & ab235296 & $1: 100$ (with $1 \%$ BSA-PBS) & Goat & Mouse \\
\hline Laminin $^{21}$ & Abcam & ab11576 & 1:100 (with $1 \%$ BSA-PBS) & Rat & Mouse, human \\
\hline Laminin (WB) & Abcam & ab11576 & 1:1000 (with $5 \%$ skim milk) & Rat & Mouse, human \\
\hline Donkey anti-goat IgG-HRP (WB) & Santa Cruz Biotechnology & sc-2020 & 1:5000 (with $5 \%$ skim milk) & Donkey & Goat \\
\hline Goat anti-rat IgG HRP (WB) & Abcam & ab7097 & 1:5000 (with $5 \%$ skim milk) & Goat & Rat \\
\hline $\begin{array}{l}\text { Goat Anti-Rabbit IgG H\&L } \\
\quad(\text { Alexa Fluor } 488)^{21}\end{array}$ & Abcam & ab150077 & $1: 100$ (with $1 \%$ BSA-PBS) & Goat & Rabbit \\
\hline $\begin{array}{l}\text { Goat Anti-Rat IgG H\&L } \\
\quad(\text { Alexa Fluor } 647)^{21}\end{array}$ & Abcam & ab150159 & $1: 100$ (with $1 \%$ BSA-PBS) & Goat & Rat \\
\hline $\begin{array}{l}\text { Goat Anti-Rat IgG H\&L } \\
\quad(\text { Alexa Fluor } 488)^{21}\end{array}$ & Abcam & ab150165 & $1: 100$ (with $1 \%$ BSA-PBS) & Goat & Rat \\
\hline $\begin{array}{l}\text { Goat Anti-Mouse IgG H\&L } \\
\quad(\text { Alexa Fluor } 568)^{21}\end{array}$ & Abcam & ab175473 & $1: 100$ (with $1 \%$ BSA-PBS) & Goat & Mouse \\
\hline $\begin{array}{l}\text { Donkey Anti-Goat IgG H\&L } \\
\quad \text { (Alexa Fluor } 647)^{21}\end{array}$ & Abcam & ab150135 & $1: 100$ (with $1 \%$ BSA-PBS) & Donkey & Goat \\
\hline
\end{tabular}

BSA, bovine serum albumin; GAPDH, glyceraldehyde-3-phosphate dehydrogenase; HRP, horseradish peroxidase; PBS, phosphate-buffered saline; PDGFR, platelet-derived growth factor receptor; $\alpha$-SMA, $\alpha$-smooth muscle actin; WB, Western blot.

saline on the same schedule. Animals were sacrificed at a time point in accord with the experimental regimen.

\section{Immunohistochemistry and Fluorescence Microscopy}

The cochleae were harvested and fixed in $4 \%$ paraformaldehyde (Electron Microscopy Sciences, Hatfield, PA) overnight at $4^{\circ} \mathrm{C}$, and then rinsed in $37^{\circ} \mathrm{C}$ phosphate-buffered saline (PBS; pH 7.3) (Life Technologies Corporation, Grand Island, NY) to remove any residual $4 \%$ paraformaldehyde. Immunohistochemistry was performed, as previously described. ${ }^{45}$ Tissue samples were permeabilized in $0.5 \%$ Triton X-100 (Sigma Aldrich, St. Louis, MO) for 30 minutes and immunoblocked for 1 hour with a solution of $10 \%$ goat serum (Sigma Aldrich, St. Louis, MO) and 1\% bovine serum albumin (BSA; Fisher Scientific, Pittsburgh, PA) in $0.02 \mathrm{~mol} / \mathrm{L}$ PBS. The specimens were incubated overnight at $4^{\circ} \mathrm{C}$, with the primary antibodies (Table 1) diluted in 1\% BSA-PBS. After three washes in PBS for 30 minutes, the samples were incubated with secondary antibodies for 1 hour at room temperature. Capillaries were labeled with lectin Griffonia simplicifolia
IB4 conjugated to Alexa Fluor 568 (Life Technologies, Eugene, OR), Alexa Fluor 488 (Life Technologies, Eugene, OR), or Alexa Fluor 647 (Life Technologies). The tissues were washed three times in PBS for 30 minutes, mounted (H-1200; Vector Laboratories, Burlingame, CA), and visualized under an FV1000 Olympus laser-scanning confocal microscope (Olympus, Tokyo, Japan).

\section{Real-Time Quantitative PCR}

The procedure used for real-time quantitative PCR was previously described. ${ }^{48}$ Total RNA from strial vascularis of control and noise-exposed groups was extracted separately with RNeasy (Qiagen, Valencia, CA). Each group of three mice was analyzed for $T g f b l$ and Gapdh mRNA with the real-time quantitative PCR. The sample for total RNA was reverse transcribed with a RETROscript kit (Invitrogen, Carlsbad, CA). cDNA synthesized from total RNA was diluted 10-fold with DNase-free water, and each cDNA sample was independently measured three times. Transcripts were quantitated by gene expression assay (Invitrogen, 
Carlsbad, CA): Tgfbl (Mm 01178820_m1), Acta2 (Mm00725412_s1), Col4a1 (Mm01210125_m1), Lama2 (Mm00550083_m1), and Gapdh (Mm99999915_g1) on a model 7300 real-time PCR system (Biosystems, Foster City, CA). The real-time PCR was cycled at $95^{\circ} \mathrm{C}$ for 20 seconds, 40 cycles at $95^{\circ} \mathrm{C}$ for 1 second, and $60^{\circ} \mathrm{C}$ for 20 seconds. Mouse Gapdh was the endogenous control. Quantitative PCR was performed per the guidelines provided by Applied Biosystems (Foster City, CA) and analyzed using the comparative $\mathrm{C}_{\mathrm{T}}$ method.

\section{ELISA}

TGF- $\beta 1$ protein level in the mouse stria vascularis before and 1 and 2 weeks after noise exposure was measured by enzyme-linked immunosorbent assay (ELISA). For the measurement, whole mounted stria vascularis from each group $(n=6)$ was assessed. The level of TGF- $\beta 1$ was estimated with an ELISA kit (Mouse TGF beta 1 ELISA Kit; Abcam, Cambridge, MA) used per company instructions. The fluorescence signals reflected the level of TGF- $\beta 1$ concentration and were detected with a Tecan GENios Plus microplate reader (Tecan Group Ltd., San Jose, CA) at an excitation wavelength of $450 \mathrm{~nm}$, with the emission acquired through a 560-nm filter. To test the ability of the PCs transfected with the AAV1-vascular endothelial growth factor (VEGF)-A 165 viral vector (Oregon Health \& Science University, Portland, OR) to drive VEGF-A ${ }_{165}$ expression in the cochlear stria vascularis, an ELISA assay (Mouse VEGF-A ELISA Kit; Abcam, Cambridge, MA; used per company instructions) was used to measure VEGF$\mathrm{A}_{165}$ protein levels in the stria vascularis 2 weeks after transplantation of AAV1-green fluorescent protein (GFP) transfected PCs and AAV1-VEGF-A 165 transfected PCs. Whole mounted stria from each group $\left(n_{\text {control }}=3\right.$, $n_{\mathrm{pc} \text { transplated }}=4$ ) were assessed. The fluorescence signal, reflecting concentration of VEGF- $\mathrm{A}_{165}$, was detected with a Tecan GENios Plus microplate reader at an excitation wavelength of $450 \mathrm{~nm}$, with the emission acquired through a $560-\mathrm{nm}$ filter. Because the total protein extracted from cochleae in different groups was different, to avoid bias, VEGF- $A_{165}$ protein level per milligram was compared with total protein between the groups.

\section{Western Blot Analysis}

Collagen IV, laminin, and $\alpha$-SMA levels in the mouse stria vascularis before and after noise exposure were measured by Western blot analysis. For Western blot analysis, total protein $(50 \mu \mathrm{g})$ from each group $(n=3)$ was added to a 10\% SDS-polyacrylamide gel (Bio-Rad Laboratories Inc, Hercules, CA) to detect collagen IV, laminin, and $\alpha$-SMA. Proteins were electrophoretically transferred to polyvinylidene difluoride membranes (EMD Millipore Corporation, Billerica, MA) and blocked with nonfat milk (Nestle Baking, Solon, $\mathrm{OH})$ for 1 hour at room temperature.
Specific immunodetection was performed by incubation with primary antibodies (Table 1), either anti-collagen IV antibody diluted 1:1000 or anti-laminin antibody diluted $1: 1000$ (or anti- $\alpha$-SMA antibody diluted 1:1000) in skim milk overnight at $4{ }^{\circ} \mathrm{C}$. After three washes with tris-buffered saline (Bio-Rad Laboratories Inc., Hercules, CA) with Tween 20 (Bio-Rad Laboratories Inc.), the membranes were incubated for 1 hour with secondary antibody (Table 1), and antigens were assessed using ECL Plus Western Blot Detection Reagents (Amersham, Arlington Heights, IL).

\section{Primary PC Line and TGF- $\beta 1$ Treatment}

To investigate if TGF- $\beta 1$ signals the PC-tomyofibroblast-like transition, purified strial PCs at the third passage were divided into control and TGF- $\beta 1-$ treated groups. ${ }^{49}$ PCs at a density of $1 \times 10^{5}$ cells $/ \mathrm{mL}$ were plated in collagen-coated dishes (MatTek Corporation, Ashland, MA) and cultured in PC culture medium (ScienCell Research Laboratories, Carlsbad, CA) containing human TGF- $\beta 1$ protein (Abcam) at different concentrations (0, 1, and $5 \mathrm{ng} /$ $\mathrm{mL}$ ) for 24 hours. At the end of the experiment, PCs were fixed with $4 \%$ paraformaldehyde for 15 minutes, permeabilized with $0.25 \%$ Triton for 30 minutes, and triple immunolabeled with antibody for platelet-derived growth factor receptor $\beta, \alpha$-SMA (Table 1), and Hoechst, a fluorescence dye for cell nuclei $(1: 10,000$; Thermo Fisher Scientific, Waltham, MA). The PCs were examined and recorded under an FV1000 Olympus laser-scanning confocal microscope. A total of 20 images were recorded from each treatment group. The PC transition percentage was detected using ImageJ software version 1.52p (NIH, Bethesda, MD; https://imagej.nih.gov/ij, last accessed March 7, 2020).

\section{D Matrigel Cell Co-Culture}

To determine the functional impact of transformed PCs on the formation of capillary-like networks and the expression of matrix proteins, including collagen IV and laminin, two experimental groups were set up. One was a capillary-like network model formed by ECs at concentration of $3.0 \times 10^{5}$ cells $/ \mathrm{mL}$ alone on three-dimensional (3D) Matrigel matrix (BD Bioscience, Franklin Lakes, NJ) for 6 hours in a $37^{\circ} \mathrm{C}$, $5 \% \mathrm{CO}_{2}$ incubator, followed by normal PCs (encoded with pmOrange2-N1 fluorescent protein, $3.0 \times 10^{5}$ cells $/ \mathrm{mL}$ ) added to the culture medium for an additional 6 hours. ${ }^{50}$ Another was a capillary-like network model formed by ECs at concentration of $3.0 \times 10^{5}$ cells $/ \mathrm{mL}$ alone on the $3 \mathrm{D}$ Matrigel matrix for 6 hours, followed by transdifferentiated PCs (same cell density) added to the culture medium for an additional 6 hours. ${ }^{50}$ The transdifferentiated PCs were produced by pretreating the PCs with TGF- $\beta 1(5 \mathrm{ng} / \mathrm{mL})$ for 24 hours. The functional effect of the transdifferentiated PCs on capillary-like branch formation was assessed, including a count of the number of branches and branch points from six 
samples per group. The functional effect of transdifferentiated PCs on expression of collagen IV and laminin was measured using immunofluorescence labeling methods. The fluorescence intensity was detected by ImageJ software. The experiments on the two groups were conducted at the same time, and images were recorded at the same confocal settings. The data (the number of capillary-like branches and branch cross points as well as the collagen IV and laminin levels of collagen IV and laminin for each group) were expressed as means $\pm \mathrm{SD}$.

\section{RT-PCR}

Neo-PCs were detached with a solution of trypsin-EDTA (Invitrogen Corporation, Carlsbad, CA), collected in a 5-mL polypropylene round-bottom tube, and centrifuged at $300 \times g$ for 5 minutes. RNA was extracted with an RNeasy microkit, cDNA was synthesized with a RETROscript kit for RT-PCR, and both were used according to the manufacturer's instructions. The RT-PCR was cycled at $95^{\circ} \mathrm{C}$ for 2 minutes, up to 30 cycles at $94^{\circ} \mathrm{C}$ for 30 seconds, $60^{\circ} \mathrm{C}$ for 30 seconds, $72^{\circ} \mathrm{C}$ for 40 seconds, and a final 5-minute extension at $72^{\circ} \mathrm{C}$. Genes of interest included Gapdh, Itgbl, Cd34, Cd44, Thyl, and Slit3. Forward and reverse primers (Table 2) and reagents in the RETROscript kit were prepared according to the manufacturer's instructions. PCR products were separated and analyzed by $1.5 \%$ agarose gel electrophoresis.

\section{Transmission Electron Microscopy}

Cochleae from control and noise-exposed groups at 2 weeks postexposure were perfused and fixed in a fixative of $4 \%$ (wt/ vol) paraformaldehyde and $0.1 \%$ (vol/vol) glutaraldehyde (Electron Microscopy Sciences, Hatfield, PA) in $0.1 \mathrm{~mol} / \mathrm{L}$ phosphate buffer overnight. Strial tissues were dissected and post fixed in 1\% osmium (Electron Microscopy Sciences, Hatfield, PA). Tissues were dehydrated with a graded alcohol series and embedded in Embed 812 (Electron Microscopy Sciences). Sections ( $1 \mu \mathrm{m}$ thick) were made to identify the blood vessels with light microscopy, when the area of interest was visible. Ultrathin sections ( $80 \mathrm{~nm}$ thick) were obtained, using a diamond knife (Diatome, Hatfield, $\mathrm{PA}$ ) and an $\mathrm{AO} /$ Reichter ultracut-E microtome (Microtome Service Company, Liverpool, NY), mounted on formvar-coated single-slot copper grids, and counterstained with $1 \%$ aqueous uranyl acetate (Electron Microscopy Sciences) for 1 hour. Systematic analysis was made in tissue sections containing the microdissected stria vascularis. Transmission electron microscopy observations and digital image capture were made using an FEI Tecnai transmission electron microscope T12 TEM-120 KV (Hillsboro, OR). All sections are systematically analyzed at low $(1100 \times$ to $3200 \times)$ and highermagnification view $(4000 \times$ to $11,000 \times)$. All sections were studied for the presence of vesicles in the ECs, PCs, and perivascular basement membrane alterations (ie, thickening and disruption).

\section{AAV1-VEGF- $A_{165}$ Viral Vector Construct}

The $p A A V-5 H R E-C A G-V E G F-A 165-P 2 A-G F P$ was constructed by replacing EF1a-DIO-oChIEF (E163A/T199C)P2A-dTomato in pAAV-EF1a-DIO-oChIEF (E163A) T199C)-P2A-dTomato-WPRE-BGHpA (51094; Addgene, Watertown, MA) with 5HRE-CAG-VEGF-A165-P2A-GFP, and was synthesized at Genscript (Piscataway, NJ). hVEGF-A165 gene expression is under control of a hypoxia response enhancer, ${ }^{51}$ in which hVEGF-A165 will only be produced when the cochlea is stressed by hypoxia. All recombinant AAV serotype 1 vectors were produced at Oregon Health \& Science University. The titer of the $r A A V$ CAG-flex-rev-hVEGF-A165-P2A-GFP was $1.4 \times 10^{13}$ genome copies $/ \mathrm{mL}$, and the titer of $p A A V-5 H R E-C A G$ $V E G F-A 165-P 2 A-G F P$ was $5.1 \times 10^{13}$ viral genomes $/ \mathrm{mL}$.

\section{AAV1-VEGF- $A_{165}$ Viral Vector Transfection of PCs in Vitro}

The primary PC cell line was generated from C57BL/6J mouse cochleae by a well-established mini-chip protocol, as previously described. ${ }^{49} \mathrm{PCs}$ at passage 3 were grown in 24-well plates in $500 \mu \mathrm{L}$ of culture medium. The next day, the cells were transfected with either AAVI-GFP (control null) or AAVI-HER-VEGF-A165-GFP at $3 \times 10^{5}$ multiplicity of infection for 48 hours, and transfected PCs were purified with fluorescence-activated cell sorting and stored for in vivo transplantation.

\section{Delivery of PCs to the Cochlea in Vivo}

Mice at 3 weeks after noise exposure were anesthetized and maintained at $37^{\circ} \mathrm{C}$ on a circulation water heating pad (Kent Scientific, Torrington, CT). Animal eyes were protected with lubricating ointment (Dechra, Overland Park, KS). Surgery was performed under an operating microscope. A postauricular skin incision was made to access the temporal bone, a small hole was made in the posterior semicircular canal and lateral semicircular canal with a 30-gauge syringe needle, and the hole was left open for a couple of minutes until no perilymph leakage was obvious. A PC suspension $\left(1 \times 10^{5}\right.$ cells in $20 \mu \mathrm{L}$ of Dulbecco's PBS) was perfused through this hole at a rate of $5 \mu \mathrm{L} /$ minute using a standard syringe pump (MINJ-PD-S100; Tritech Research, Los Angeles, CA) controlled by a microINJECTOR All-Digital Positive Displacement System (MINJ-PD). The tube was then removed, the semicircular canals were sealed with a muscle and fibrin adhesive, and the skin was closed with sutures.

\section{EdU Labeling of the Strial Vasculature}

5-Ethynyl-2'-deoxyuridine (EdU) (Life Technologies) was given at a dose of $25 \mathrm{mg} / \mathrm{kg}$ body weight in a solution of 5 $\mathrm{mg} / \mathrm{mL}$ PBS once every 24 hours by i.p. injection for a total of 5 consecutive days. The mice were anesthetized with a cocktail of solution of ketamine hydrochloride xylazine 
Table 2 Primers Applied

\begin{tabular}{|c|c|c|c|c|}
\hline Gene & Primer & Oligonucleotide sequence & $\mathrm{Tm},{ }^{\circ} \mathrm{C}$ & Size, bp \\
\hline \multirow[t]{2}{*}{ Gapdh } & $\mathrm{F}$ & 5'-ATGTGTCCGTCGTGGATCTGA-3' & 58.9 & 132 \\
\hline & $\mathrm{R}$ & $5^{\prime}$-AGACAACCTGGTCCTCAGTGT-3' & 58.0 & \\
\hline \multirow[t]{2}{*}{ Itgb1 } & $\mathrm{F}$ & $5^{\prime}-$ CAATCGCAGCAAAGGGATGG-3' & 59.9 & 263 \\
\hline & $\mathrm{R}$ & $5^{\prime}$-AGCCAATGCGGAAGTCTGAA-3' & 60.0 & \\
\hline \multirow[t]{2}{*}{ Cd34 } & $\mathrm{F}$ & $5^{\prime}$-GGGAGCCACCAGAGCTATTC-3' & 57.5 & 300 \\
\hline & $\mathrm{R}$ & 5'-CACCACATGTTGTCTTGCTGA-3' & 55.7 & \\
\hline \multirow[t]{2}{*}{ Cd44 } & $\mathrm{F}$ & 5'-GAATTCTGCGCCСTCGGTT-3' & 60.8 & 373 \\
\hline & $\mathrm{R}$ & $5^{\prime}$-GTGTTGGACGTGACGAGGAT-3' & 60.0 & \\
\hline \multirow[t]{2}{*}{ Thy1 } & $\mathrm{F}$ & $5^{\prime}$-ACTCTTGGCACCATGAACCC-3' & 60.3 & 344 \\
\hline & $\mathrm{R}$ & $5^{\prime}-\mathrm{CCCGAGACTTGAAGCTCACA-3^{ \prime }}$ & 59.7 & \\
\hline \multirow[t]{2}{*}{ Slit3 } & $\mathrm{F}$ & 5'-AGATCAACTGTCTGCGGGTG-3' & 60.0 & 400 \\
\hline & $\mathrm{R}$ & $5^{\prime}$-AGCTTCTGGTTGGAGCAGTC-3' & 60.0 & \\
\hline
\end{tabular}

F, forward; $R$, reverse; Tm, temperature.

(100 mg/kg; Henry Schein, Melville, NY) and 2\% xylazine hydrochloride (10 mg/kg; LLOYD Inc., Shenandoah, IA) in saline by an i.p. injection. Lectin-DyLight 649 (Vector Laboratories, Burlingame, CA) diluted in $0.1 \mathrm{~mol} / \mathrm{L} \mathrm{PBS}$ buffer to a concentration of $20 \mu \mathrm{g} / \mathrm{mL}$ was injected via i.v. retro-orbital sinus for labeling blood vessels. Cochleae were isolated and then fixed in $4 \%$ paraformaldehyde overnight at $4^{\circ} \mathrm{C}$. Next day, whole mounts of stria vascularis were carefully isolated. The proliferating cells in the stria were assayed with a Click-iT Plus EdU Alexa Fluor 555 imaging kit (Life Technologies, Eugene, OR) following the manufacturer's recommendation. Briefly, the stria were washed in PBS and permeabilized in 0.5\% Triton X-100 (Sigma, St. Louis, MO) for half an hour, and then immunoblocked for 30 minutes with $3 \%$ BSA in PBS, followed by incubation for 30 minutes in the EdU cocktail (protected from the light) and washed once in 3\% BSA in PBS. The stria was then washed with PBS and blocked with $10 \%$ goat serum for 1 hour, and incubated with a primary antibody, rabbit anti- platelet-derived growth factor receptor $\beta$ (Abcam), in 1\% BSA in PBS overnight at $4^{\circ} \mathrm{C}$. The next day, after three washes in PBS, the samples were incubated with the secondary antibody, Alexa Fluor 488-conjugated goat antirabbit IgG (Invitrogen, Eugene, OR), for 1 hour at room temperature. After three washes in PBS for 30 minutes, the tissues were mounted in mounting medium (H-1200) and visualized under an FV1000 Olympus laser-scanning confocal microscope. The EdU-positive cell population was calculated as follows:

$$
\text { EdU positive cells }=\frac{\text { numbers of EdU positive cell }}{\text { area of stria vascularis }}
$$

\section{Measurement of Capillary Density}

The entire length of the mouse stria vascularis (from apex to base) was captured. Capillaries in the stria vascularis were visualized by lectin 649 labeling under an FV1000 Olympus confocal microscope. The blood vessels were traced manually, and the area of the stria was determined from a differential interference contrast image. The pixel area of the capillary and pixel area of the stria were determined using ImageJ software. Capillary density as a percentage of the stria was calculated as follows: ${ }^{1}$

$$
\frac{\text { Pixel area of capillaries }}{\text { Pixel area of stria vascularis }} \times 100 \%
$$

PC transition was recognized by their shape and being positive for $\alpha$-SMA in the capillary region. ImageJ software was used to measure the lumen diameters at both $\mathrm{PC}$ and non-PC transition locations. Lumen diameters near PC and non-PC transition locations were measured at the maximal PC transition location. All image panels presented in the article were constituted from individual images processed and labeled using Adobe Photoshop version CC 2017 (Adobe Inc, San Jose, CA) with a resolution of 300 dots per inch.

\section{Preparation of the Fluorescent-Labeled Blood Cell Suspension}

Donor mice were deeply anesthetized with ketamine/xylazine cocktail by i.p. injection, as stated above. The mice were exsanguinated using cardiac puncture, $1 \mathrm{~mL}$ of blood was collected in heparin (15 IU/mL blood) (Mylan Institutional LLC, Rockford, IL), and blood was centrifuged at $3000 \times g$ for 3 minutes at $4^{\circ} \mathrm{C}$. Plasma was removed and replaced with PBS, and the blood cell pellet was centrifuged and washed three times at $3000 \times g$ for 3 minutes at $4^{\circ} \mathrm{C}$. Packed red blood cells

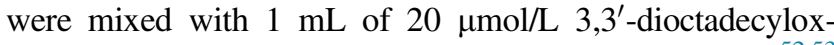
acarbocyanine perchlorate (Sigma Aldrich) PBS solution. ${ }^{52,53}$ The solution was incubated at room temperature in the dark for 30 minutes, centrifuged, and washed three times with PBS. Before injection, the blood cells were suspended in PBS to achieve a hematocrit of $30 \%$. 

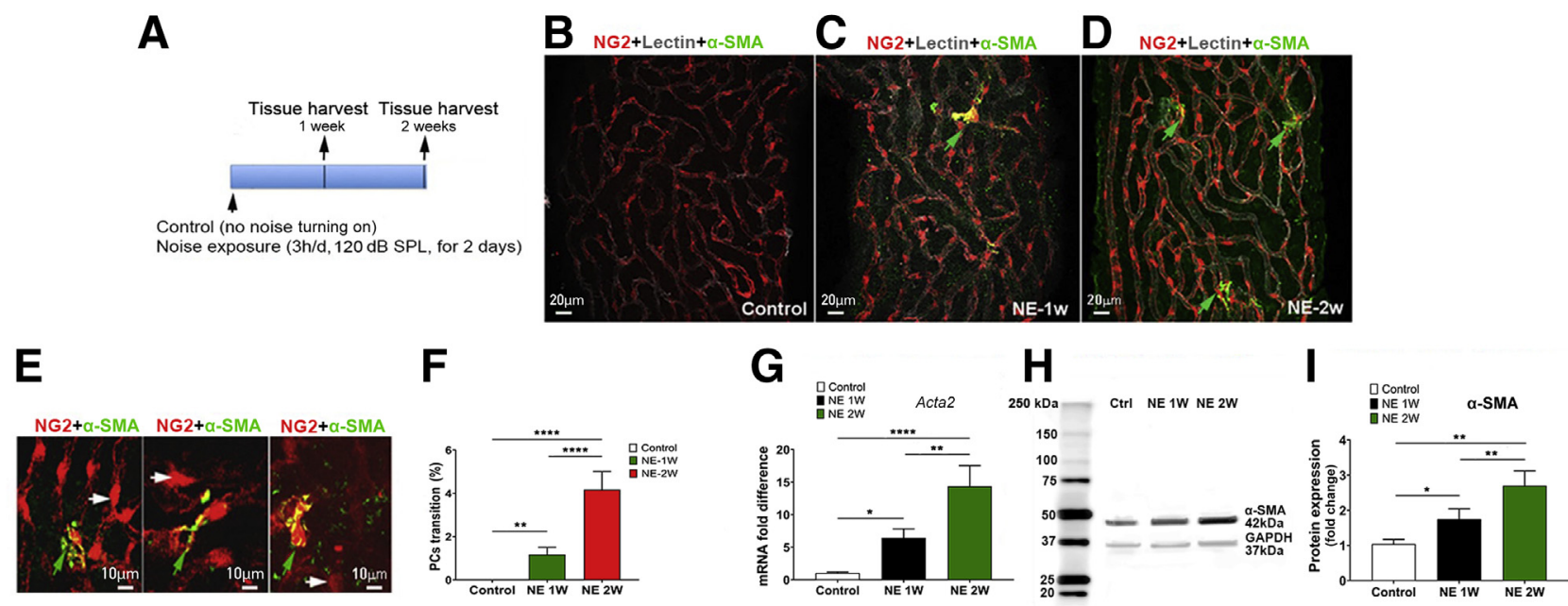

Figure 1 Pericyte (PC)-to-myofibroblast cell-like transition in the stria after noise exposure (NE). A: Scheme of the experimental design. B-D: Confocal projection images of the stria from the control (Ctrl), and 1 and 2 weeks after exposure to loud sound. Some of the neural/glial antigen 2-positive (NG2 ${ }^{+}$) PCs in different regions of the strial capillaries are positive for $\alpha$-smooth muscle actin ( $\alpha$-SMA; green arrows) at 1 and 2 weeks after noise exposure. E: Highmagnification images show PCs positive for $\alpha$-SMA (green arrows) and normal PCs (NG2 ${ }^{+} / \alpha-S M A^{-}$; white arrows). F: PC transition percentage in control, and 1 and 2 weeks after noise exposure $\left[F_{\mathrm{PC}}\right.$ transition $\left.(2,15)=103.95\right]$. G: Real-time quantitative PCR shows that the mRNA level of $A c t a 2$ is significantly upregulated at 1 and 2 weeks after noise exposure $\left[F_{\text {Acta2 mRNA }}(2,6)=33.495\right] . \mathbf{H}$ and I: A representative Western blot and Western blot analysis of $\alpha$-SMA, showing increased protein expression at 1 and 2 weeks following noise exposure $\left[F_{\mathrm{a}-S M A}\right.$ protein $\left.(2,6)=22.188\right]$. Data are expressed as means $\pm S D(F, G$, and I). $n=6$ in each group (F); $n=3$ in each group ( $\mathbf{G}$ and $\mathbf{I}) .{ }^{*} P<0.05,{ }^{*} P<0.01$, and ${ }^{* * * *} P<0.0001$ (one-way analysis of variance). Scale bars: $20 \mu \mathrm{m}$ (B-D); $10 \mu \mathrm{m}$ (E). GAPDH, glyceraldehyde-3-phosphate dehydrogenase; SPL, sound pressure level.

\section{Intravital Fluorescence Microscopy}

The mice from noise-exposed, noise-exposed treated with PCs $^{\text {AAV1-GFP }}$ (control null), and noise-exposed treated with $\mathrm{PCs}^{A A V 1-V E G F-A 165}$ groups at 2 weeks after PC treatment were anesthetized, wrapped on a heating pad, and maintained at a rectal temperature of $37^{\circ} \mathrm{C}$. A vessel window was generated using a small knife blade to scrap the lateral wall bone until a thin spot was cracked (Shi et $\mathrm{al}^{54}$ ). The bone chips were removed with small wire hooks. The vessel window was covered with a cut coverslip (12-542A; Thermo Fisher Scientific) to preserve normal physiological conditions and provide an optical view for recording vessel images. Blood vessels were visualized using fluorescein isothiocyanate-dextran (2000 kDa; Sigma Aldrich) as a contrast medium to fluorescently label the bloodstream. The fluorescein isothiocyanate-dextran was administrated intravenously to the mice at a concentration of $40 \mathrm{mg} / \mathrm{mL}$ in 100 $\mu \mathrm{L}$ physiological solution over a 5-minute interval. Meanwhile, a $100 \mu \mathrm{L}$ blood cell suspension was infused into the femoral vein for tracking blood flow velocity. Strial images were recorded with a Zeiss LSM 7 MP system (Zeiss, Oberkochen, Germany) with a long working distance objective $(8.4 \mathrm{~mm} ; 10 \times)$ at 2 frames/second. Blood flow was directly observed in real time on a video monitor. More than 350 images were acquired per video to ensure successful analysis of flow velocity. Vascular diameter and blood flow velocity, determined offline from the captured video frames, were analyzed by a cross-correlation method using ImageJ. In brief, the luminal intensity of spatial structure in the image sequences was cross correlated, and blood flow velocity was calculated by tracing the 3,3'-dioctadecyloxacarbocyanine perchlorate-stained blood cells in the spatial distance between image locations by the time difference: ${ }^{55}$

$$
\text { velocity }=\frac{\text { distance }(\mu \mathrm{m})}{\operatorname{time}(\mathrm{s})}
$$

Volume flow was estimated by the following equation: flow $=$ velocity $\times$ cross-sectional area of the vessel. Vascular velocity and vascular volume were averaged as means \pm SD.

\section{Auditory Testing}

An auditory brainstem response audiometry test to pure tones was used to evaluate hearing function. Animals were anesthetized with an i.p. injection of ketamine/xylazine cocktail, and placed on a heating pad in a sound-isolated chamber. Needle electrodes were placed subcutaneously near the test ear, at the vertex, and on the contralateral ear. Each ear was stimulated separately with a closed-tube sound delivery system sealed into the ear canal. The auditory brainstem response to a 1-millisecond rise-time tone burst at 4, 8, 12, 16, 24, and 32 $\mathrm{kHz}$ was recorded, and thresholds were obtained for each ear. Threshold is defined as an evoked response of $0.2 \mu \mathrm{V}$.

\section{Measurement of EP}

EP was measured for control, noise-exposed, noise-exposed treated with PCs ${ }^{\mathrm{AAV} 1-\mathrm{GFP}}$, and noise-exposed treated with $\mathrm{PCs}^{\text {AAVI-VEGF-A165 }}$ groups. The method follows as previously described, with a minor modification. ${ }^{56}$ A silver chloride reference electrode was placed under the skin. A glass micropipette filled with $150 \mathrm{mmol} / \mathrm{L} \mathrm{KCl}$ was advanced to the round 

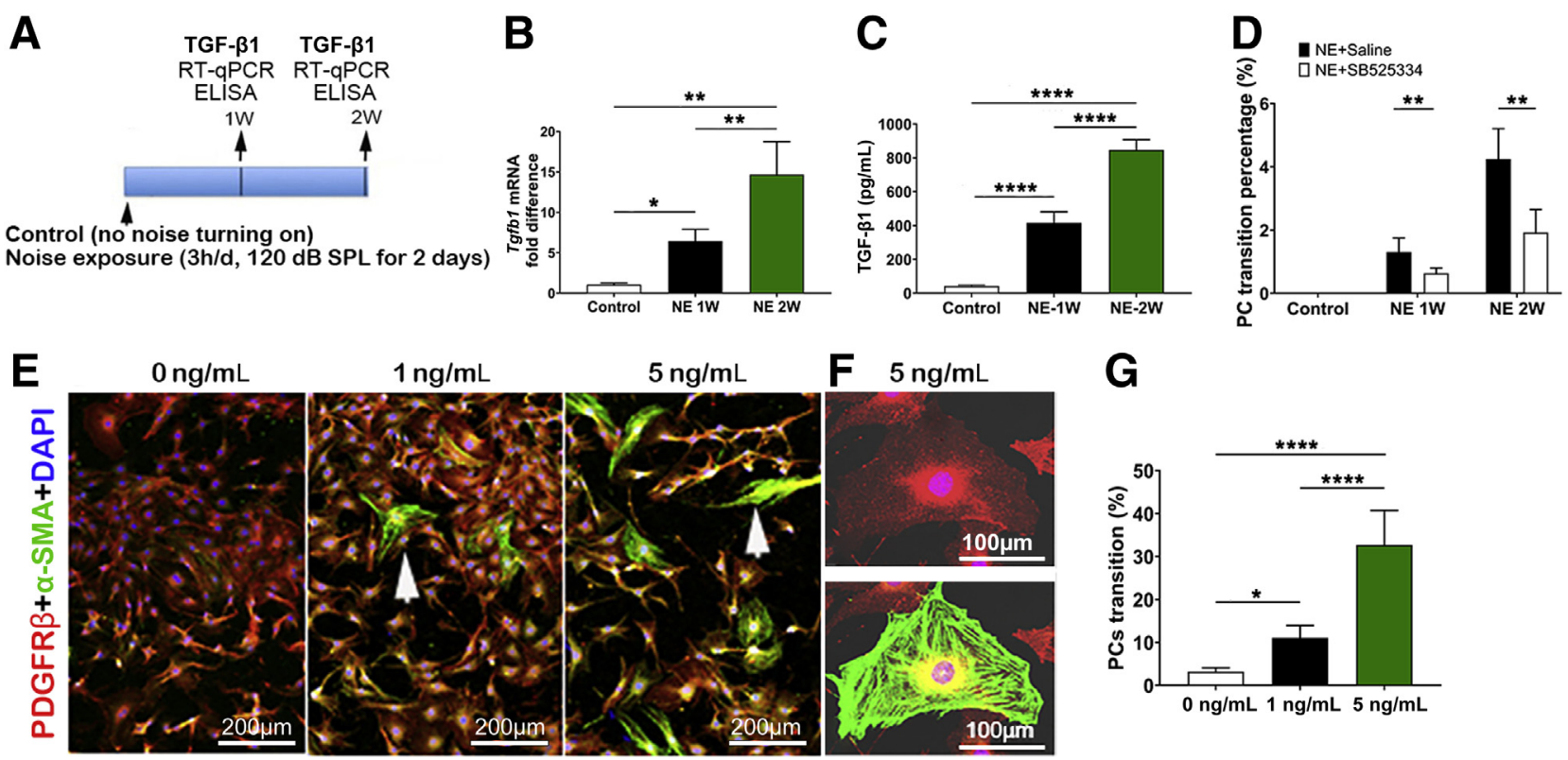

G

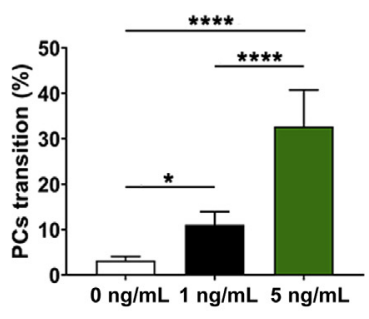

Figure 2 Pericyte (PC) transition is highly associated with transforming growth factor (TGF)- $\beta 1$ in an in vitro cell line model. A: An illustration of the experimental setting. B and C: Tgfb1 expression at both the transcription and protein levels is highly up-regulated 1 and 2 weeks after loud sound exposure $\left[F_{\text {Tgfb1 mRNA }}(2,8)=22.41 ; F_{\text {Tgfb1 protein }}(2,15)=364.15\right]$. D: Percentage of PC-to-myofibroblast transition in the stria after loud sound exposure in control, noise-exposed (NE) + saline, and noise-exposed + TGF- $\beta 1$ inhibited (SB525334) groups [ $t_{\mathrm{NE}} 1$ week $(10)=3.48 ; t_{\mathrm{NE}} 2$ weeks $(10)=4.53, t$-test]. E: Confocal projection images show TGF- $\beta 1$ induces $\alpha$-smooth muscle actin ( $\alpha$-SMA) + PC transition (white arrows) at different concentrations of TGF- $\beta 1$. F: Highmagnification confocal images further show a PC can strongly express $\alpha$-SMA fibers and continue to express PC marker proteins, such as platelet-derived growth factor receptor (PDGFR) $\beta$. G: Percentage of PC-to-myofibroblast transition in cultured PCs after TGF- $\beta 1$ treatment is dose dependent $\left[F_{\mathrm{PC}}\right.$ transition $(2,15)=56.74]$. Data are expressed as means \pm SD (B-D and $\mathbf{G}) . n=3$ in each group $(\mathbf{B}) ; n=6$ in each group $(\mathbf{C}, \mathbf{D}$, and $\mathbf{G}) .{ }^{*} P<0.05, * * P<0.01$, and $* * * * P 0.0001$ (one-way analysis of variance). Scale bars: $200 \mu \mathrm{m}(\mathrm{E}) ; 100 \mu \mathrm{m}(\mathbf{F})$. ELISA, enzyme-linked immunosorbent assay; RT-qPCR, quantitative RT$\mathrm{PCR}$; SPL, sound pressure level.

window membrane, and the offset was adjusted to zero baseline. Entry of the electrode tip into scala media is characterized by a positive potential jump during recording. The pipette was advanced until a stable potential was observed. The potential was amplified (model 3000 AC/DC differential amplifier; A-M Systems Inc, Sequim, WA), recorded via an A-D converter (Fluke II multimeter; Fluke Corporation, Everett, WA), and computer recorded. The collected data were exported and waveform reconstructed and analyzed in Signal Express 2015 (National Instruments, Austin, TX).

\section{Statistical Analysis}

Data are presented as means \pm SD and were evaluated by using the $t$-test for two groups or by analysis of variance for comparisons of three or more groups. A 95\% confidence level was considered statistically significant. GraphPad Prism 8.0 (GraphPad Software, San Diego, CA) and SPSS 25.0 software (IBM, Armonk, NY) were used for the analysis.

\section{Results}

The PC Transition from $\mathrm{NG}^{+} / \alpha-\mathrm{SMA}^{-}$to $\mathrm{NG}^{+}$ $/ \alpha-\mathrm{SMA}^{+}$in the Stria after Acoustic Trauma

Cochlear strial capillaries contain a rich population of PCs. They express NG2, desmin, and platelet-derived growth factor receptor $\beta$, but are negative for $\alpha$-SMA. ${ }^{40}$ In this study, fluorescent reporter transgenic mice, whose PCs are labeled with fluorescent protein under an NG2 promoter, were exposed to broadband noise at $120-\mathrm{dB}$ sound pressure level for 3 hours for 2 consecutive days (Figure 1A). It was found that some $\mathrm{NG}^{+}{ }^{+} \mathrm{PC}$ were positive to $\alpha$-SMA at 1 week, and the number of $\mathrm{NG}^{+/} \alpha-\mathrm{SMA}^{+}$PCs slightly increased at 2 weeks after the acoustic trauma. Representative lowmagnification confocal images showing $\mathrm{PC}$ transition from $\mathrm{NG}^{+} / \alpha-\mathrm{SMA}^{-}$to $\mathrm{NG}^{+} / \alpha-\mathrm{SMA}^{+}$in control mice, and at 1 and 2 weeks following noise exposure are shown (Figure 1, B-D). High-magnification images (Figure 1E), show the $\alpha$-SMA-positive signal predominantly in the processes of a PC. The percentage of PC transition in control, and at 1 and 2 weeks following noise exposure is shown (Figure 1F). Consistent with increased immunofluorescence labeling for $\alpha$-SMA seen in the strial PCs, real-time quantitative PCR and Western blot measurements show both transcript and protein levels of $\alpha$-SMA significantly up-regulated at 1 and 2 weeks after acoustic trauma (Figure 1, G-I).

\section{PC Transition Is Associated with a TGF- $\beta 1$ Signal}

The transition of $\mathrm{NG}^{+} / \alpha-\mathrm{SMA}^{-}$PCs to $\mathrm{NG}^{+} / \alpha-$ $\mathrm{SMA}^{+}$cells is strongly related to the production of TGF- $\beta 1$. In this study, $T g f b l$ was highly overexpressed at the transcript and protein levels at 1 to 2 weeks after acoustic 

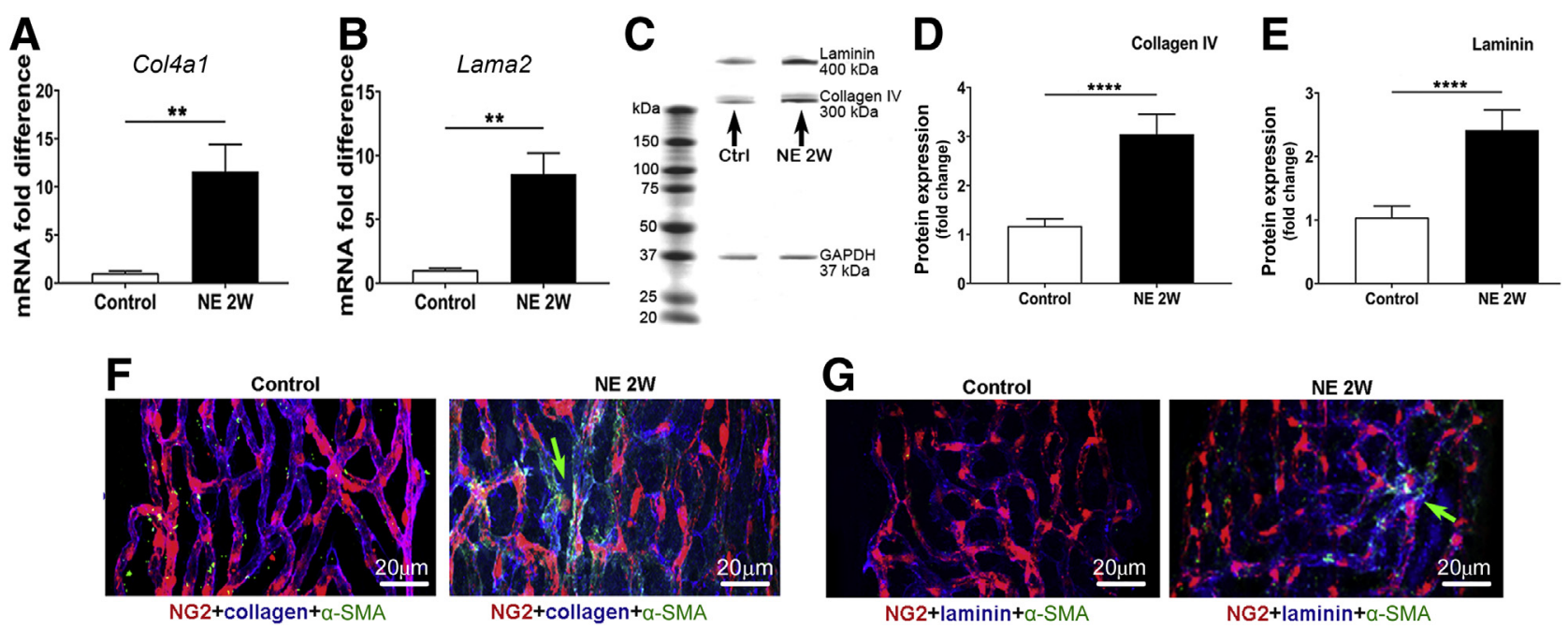

Figure 3 Collagen IV and laminin expression is increased in the strial vasculature 2 weeks after noise exposure (NE). A and B: Real-time quantitative PCR analysis shows significantly increased expression of collagen IV and laminin at the transcript level at 2 weeks following noise exposure $\left[t_{\text {col4a1 }}(4)=6.52 ; t_{\text {Lama2 }}(4)=7.81\right]$. C-E: Western blot analysis shows band intensity and fold change in collagen IV and laminin protein expression at 2 weeks after noise exposure [ $t_{\text {collagen IV }}(4)=14.55$; $\left.t_{\text {Laminin }}(4)=12.86\right]$. F and G: Representative confocal projection images show collagen IV and laminin expression in the control (Ctrl) group (left panels) and noiseexposed group at 2 weeks after noise exposure (right panels). Expression of basement proteins is particularly conspicuous in the pericyte-transformed locations (green arrows). Data are expressed as means $\pm \operatorname{SD}(\mathbf{A}, \mathbf{B}, \mathbf{D}$, and $\mathbf{E}) . n=3$ in each group $(\mathbf{A}, \mathbf{B}, \mathbf{D}$, and $\mathbf{E}) .{ }^{* *} P<0.01,{ }^{* * *} p<0.0001$ ( $t$-test). Scale bars $=20 \mu \mathrm{m}(\mathbf{F}$ and G). $\alpha$-SMA, $\alpha$-smooth muscle actin; GAPDH, glyceraldehyde-3-phosphate dehydrogenase; NG2, neural/glial antigen 2.

trauma (Figure 2A). Tgfbl at the transcript and protein levels is shown (Figure 2, B and C). Blockage of the TGF$\beta 1$ signal markedly attenuated the $\mathrm{NG}^{+} / \alpha-\mathrm{SMA}^{-} \mathrm{PCs}$ to $\mathrm{NG}^{+} / \alpha-\mathrm{SMA}^{+}$transition (Figure $2 \mathrm{D}$ ).

To further validate whether TGF- $\beta 1$ signaling initiates the PC change in phenotype, a purified strial PC primary cell line was employed at the third passage. Specifically, PCs were divided into control and TGF- $\beta 1-$ treated groups. PCs at a density of $1.0 \times 10^{5}$ cells $/ \mathrm{mL}$ were plated in collagen-coated dishes. In the control group, PCs were incubated in PC culture medium, whereas in the TGF- $\beta 1$-treated group, the PCs were incubated in culture medium also containing different concentrations of TGF- $\beta 1(0,1$, and $5 \mathrm{ng} / \mathrm{mL})$ for 24 hours. The $\mathrm{NG}^{+} / \alpha-\mathrm{SMA}^{-} \mathrm{PC}$ to $\mathrm{NG}^{+} / \alpha-\mathrm{SMA}^{+}$transition was identified by immunophenotyping. As expected, the PC transition was markedly affected by the level of TGF- $\beta 1$, with the number of PC transitions increasing in a dose-dependent manner (Figure 2, E and G). Dramatic morphology changes were also seen in phenotype changed PCs, as shown in Figure 2, E and F. Under control in vitro conditions, PCs displayed a broad filopodia morphology (Figure 2E), consistent with that previously described by Shepro and Morel. ${ }^{57}$ In contrast, transformed PCs appeared large, comprising rich myofilaments (Figure 2E). The features are better visualized under high magnification (Figure 2F). Taken together, this is evidence TGF- $\beta 1$ signaling is responsible for the post-acoustic trauma-induced PC $\mathrm{NG}^{+} / \alpha-\mathrm{SMA}^{-}$to $\mathrm{NG}^{+} / \alpha-\mathrm{SMA}^{+}$transition.

\section{Higher Expression of Extracellular Matrix Components in the Region of Transformed PCs}

Smooth muscle cells and myofibroblasts synthesize and deposit extracellular matrix components in tissue, which leads to tissue fibrosis and capillary degeneration. ${ }^{35,58,59}$ In this study, both collagen type IV and laminin, major extracellular matrix proteins in the stria, ${ }^{60}$ were significantly up-regulated at the transcriptional and protein level at 2 weeks after loud sound exposure. Increased Col4al and Lama 2 mRNA, as assessed by real-time quantitative PCR analysis is shown (Figure 3, A and B). Collagen type IV and laminin protein expression in the stria was also significantly elevated, measured by Western blot analysis (Figure 3, $\mathrm{C}-\mathrm{E})$. Furthermore, immunohistochemical examination by confocal microscopy clearly shows collagen type IV and laminin increasingly expressed in the stria. The expression was particularly conspicuous at locations of transition (Figure 3, F and G). In contrast, collagen type IV and laminin expression in nonmigrated PCs was low (Figure 3, $F$ and $G$ ). Representative confocal maximum projection images of immunofluorescence labeled collagen type IV and laminin in control and noise-exposed groups is shown (Figure 3, F and G).

\section{PCs Transitioned from $\mathrm{NG}^{+} / \alpha-\mathrm{SMA}^{-}$to $\mathrm{NG}^{+} /$ $\alpha-\mathrm{SMA}^{+}$Express More Extracellular Matrix Components}

To further determine the functional impact of transitioned PCs on expression of matrix protein, two in vitro experiments (Figure 4, A and B) were conducted. In study A, ECs alone were seeded on a 3D Matrigel matrix for 6 hours, followed by normal PCs (tagged with pmOrange2-N1 fluorescent protein; $3.0 \times 10^{5}$ cells $/ \mathrm{mL}$ ) added to the culture medium for an additional 6 hours. In study B, ECs alone were seeded on 3D Matrigel matrix for 6 hours, followed by transitioned PCs (same cell density) added to the culture medium for an additional 6 hours. The transitioned PCs 

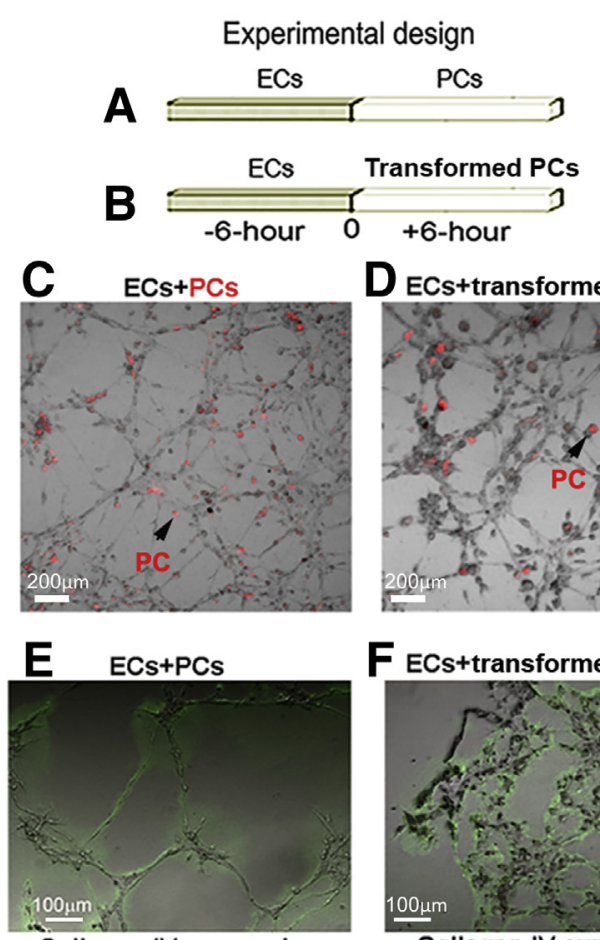

Collagen IV expression

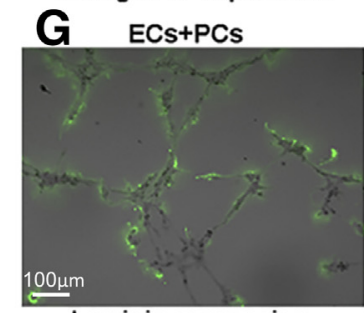

Laminin expression

I Collagen IV
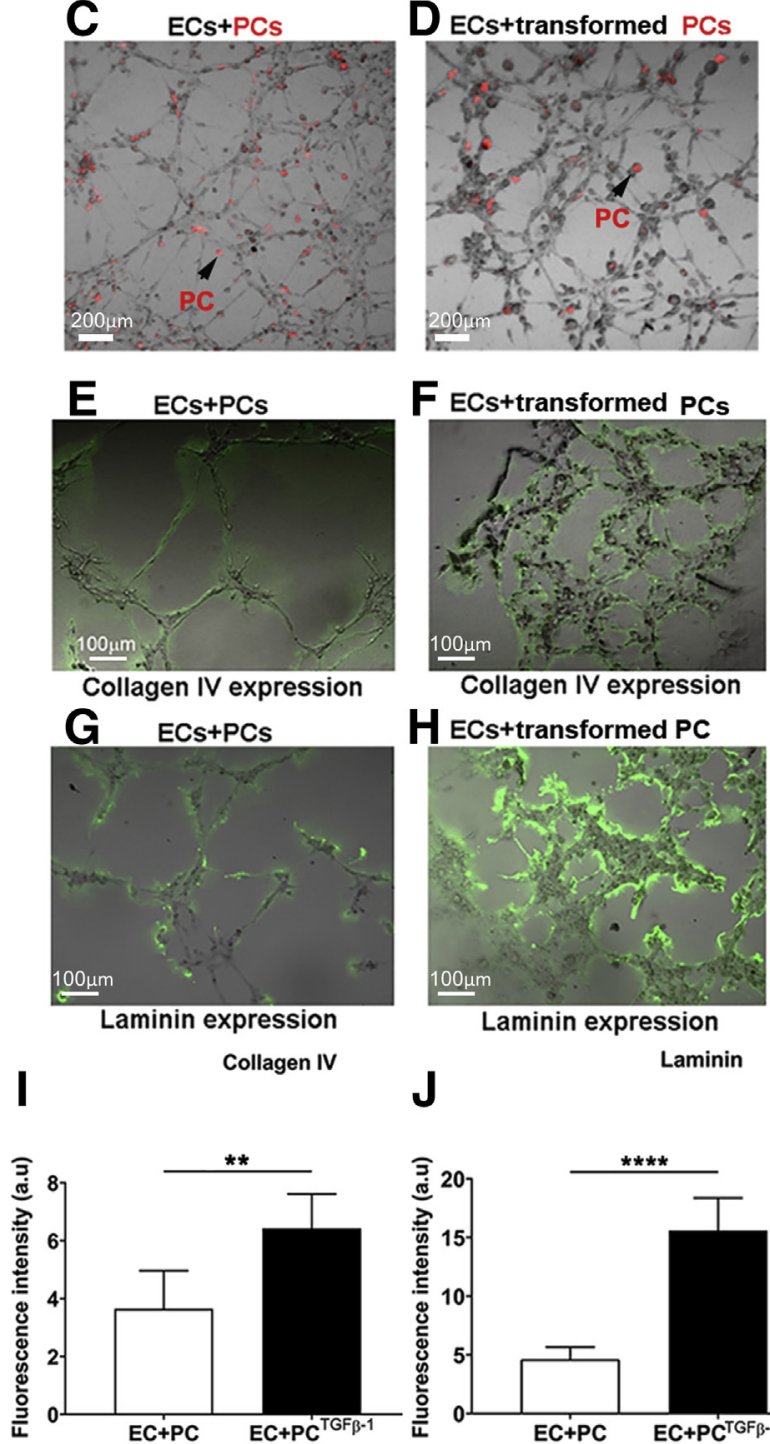

Collagen IV expression

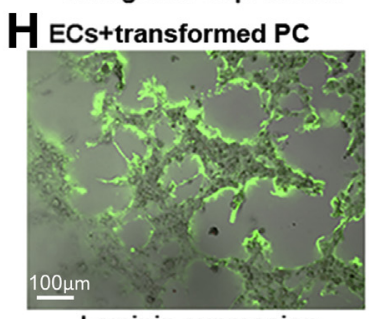

Laminin expression

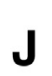

Laminin

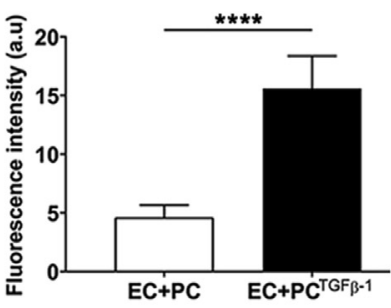

Figure 4 Increased collagen IV and laminin expression in threedimensional (3D) cell co-culture of endothelial cells (ECS) and transformed pericytes (PCs). A and B: Experimental design of in vitro 3D cell co-culture of ECs and PCs or transformed PCs for determining the effect of non-transformed and transformed PCs on capillary-like branch formation and expression of matrix proteins. C: ECs co-cultured with normal PCs for 12 hours form denser and finer capillary-like branches. D: In contrast, ECs co-cultured with transformed PCs form relatively thicker and less articulated capillary-like branches. Compared with the normal PCs in $\mathbf{C}$ (red/arrow), transformed PCs in $\mathbf{D}$ are relatively larger (red/arrow). E and F: The immunofluorescence signal for collagen IV in the control and transformed PC groups. $\mathbf{G}$ and $\mathbf{H}$ : The immunofluorescence signal for laminin in the control and transformed PC groups. I and J: Data analysis shows collagen IV and laminin fluorescence intensity in the two groups are statistically different [ $\left.t_{\text {Collagen IV }}(8)=-3.512 ; t_{\text {Laminin }}(8)=-8.247\right]$. Data are expressed as means \pm SD (I and $\mathbf{J}) . n=5$ in each group (I and $\mathbf{J}) .{ }^{* *} P<0.01$, $* * * * P<0.0001$ (t-test). Scale bars: $200 \mu \mathrm{m}$ (C and D); $100 \mu \mathrm{m}$ (E-H). a.u., arbitrary unit; TGF $\beta-1$, transforming growth factor beta 1 . were produced by pretreating the PCs with TGF- $\beta 1(5 \mathrm{ng} /$ $\mathrm{mL}$ ) for 24 hours. This treatment initiates the $\mathrm{PC} \mathrm{NG} 2^{+} / \alpha-$ $\mathrm{SMA}^{-}$to $\mathrm{NG}^{+} / \alpha-\mathrm{SMA}^{+}$transition in $>80 \%$ of the total population of treated PCs (data not shown). Interestingly, compared with the normal PCs (Figure 4C), transformed PCs (Figure 4D) were relatively larger in size. ECs cocultured with normal PCs for 12 hours formed denser and finer capillary-like branches (Figure 4C). In contrast, ECs co-cultured with transformed PCs formed relatively thicker and less articulated capillary-like branches (Figure 4D). Immunofluorescence labeling showed notably increased expression of collagen type IV and laminin in the transitioned PC co-cultured groups. Collagen IV and laminin expression in ECs + PCs and ECs + transformed PCs are shown (Figure 4, E-H). The difference in collagen IV and laminin expression between the two groups was statistically significant (Figure 4, I and J). Collectively, the data indicate the transition of PC phenotype increases expression of extracellular matrix components.

\section{Capillary Shutdown Primarily in the Region of Transformed PCs}

In this study, structural changes were noted in capillaries at sites of PC transition. Typical patterns of capillary degeneration at 2 weeks following loud sound exposure are shown (Figure 5A). A capillary constrict (narrowed), capillary narrowing, and capillary remnant at the site of a PC transition are shown (Figure 5A). Average capillary diameter in the region of PC transition was significantly decreased relative to sites where $\mathrm{PCs}$ were not transitioning (Figure 5B). Low-magnification transmission electron microscope images of a normal mouse capillary shows ECs surrounded with an even electron density of basement membrane (Figure 5C). This is better visualized under high magnification (Figure 5C). In contrast, capillary shrinkage and tissue vacuolization were observed in the noise-exposed mice at 2 weeks after noise exposure (Figure 5D). Vacuoles in the cytoplasm of ECs, surrounding strial cells and substance deposition in basement membrane (Figure 5D), are clearly seen in the noise-exposed mouse under high magnification. The data strongly suggest vascular degeneration after acoustic trauma, particularly in regions showing PC-to-myofibroblast transition.

\section{Transplantation of Neo-PCs Promotes Angiogenesis and Attenuates Reduction in Strial Vascular Density at 5 Weeks after Acoustic Trauma}

PCs induce endothelial cell proliferation and activate angiogenic processes by releasing growth factors, such as basic fibroblast growth factor, hepatocyte growth factor, epidermal growth factor, and angiopoietin. ${ }^{61-63}$ Do cochlear PCs also have the capacity to repair loud sound-damaged vessels? Cochlear neo-PCs express several mesenchymal protein genes, including Itgbl, Cd34, Cd44, Thyl, and Slit3. This 

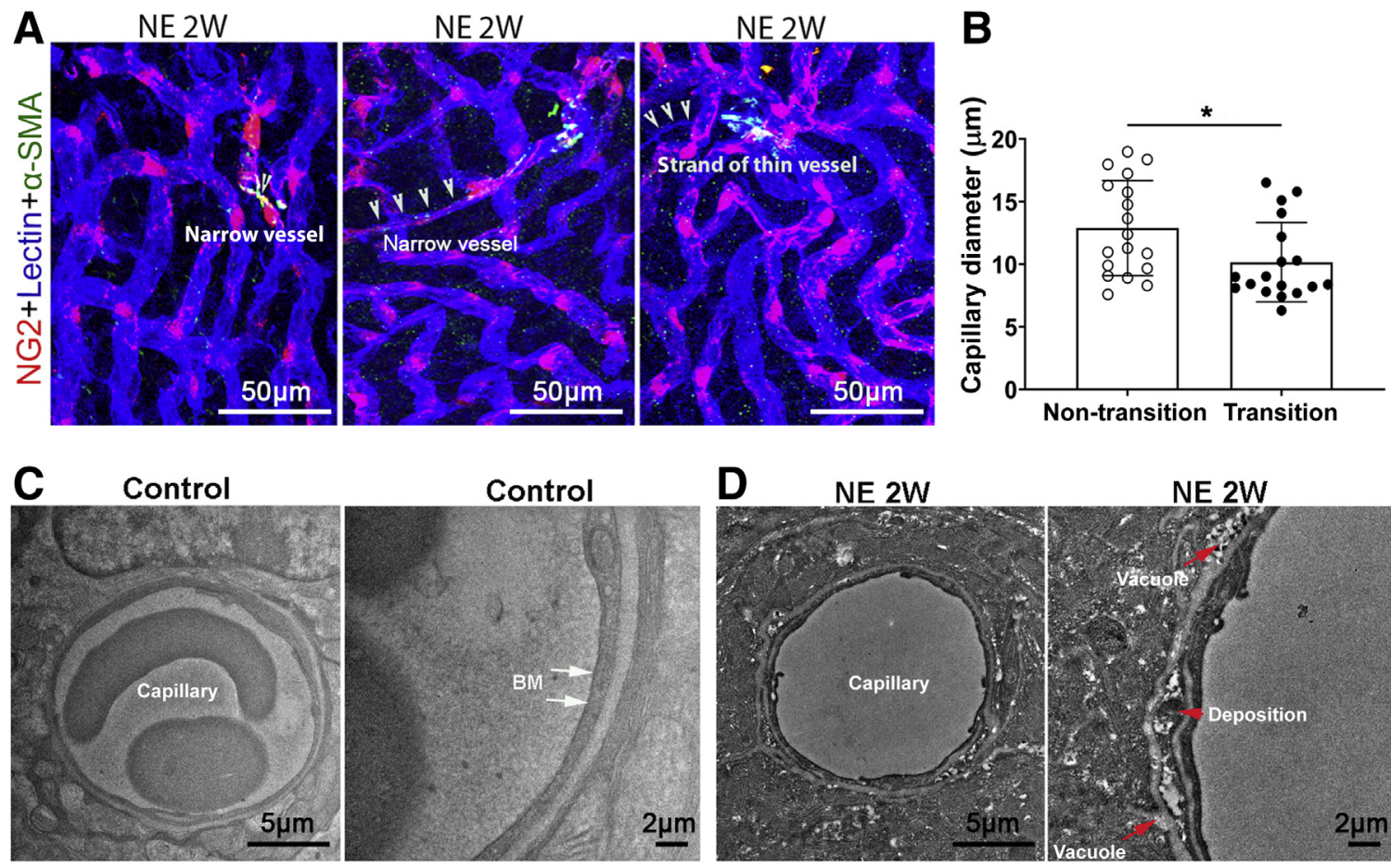

Figure 5 Capillary degeneration in the region of pericyte (PC) transition 2 weeks after noise exposure (NE). A: Representative confocal projection images show characteristic changes in capillary diameter in lectin-labeled strial microvessels at sites of PC transition (arrowheads) and non-PC transition. B: Vessel diameter in the two regions is statistically different $\left[t_{\text {Capillary Diameter }}(34)=2.34\right]$. C and D: Left and right panels: Electron micrographs under low and high magnification from control (C) and noise-exposed animals (D). C: Right panel: Under normal conditions, strial blood vessels have a smooth lumen of endothelial cells surrounded by basement membrane (BM) of even electron density (arrow). D: Right panel: Under noise-exposed conditions, the capillary is disrupted with vacuolization and substance deposition (arrow). Data are expressed as means \pm SD (B). $n_{\text {Capillary Diameter }}=6$ (B). ${ }^{*} P<0.05$ ( $t$-test). Scale bars: $50 \mu \mathrm{m}(\mathbf{A}) ; 5 \mu \mathrm{m}$ (C and D, left panels); $2 \mu \mathrm{m}$ (C and D, right panels). $\alpha$-SMA, $\alpha$-smooth muscle actin; NG2, neural/glial antigen 2.

expression profile suggests pluripotency and potential for tissue regeneration (Figure 6, A and B). And, indeed, in our in vitro cell line-based three-dimensional co-culture model, the neo-PCs do dramatically promote sprouting angiogenesis (Figure 6, C and D).

It was next investigated whether PC transition-caused vascular degeneration could be reversed by transplantation of neo-PCs. To test this, either control PCs or conditioned PCs were locally transplanted through the posterior semicircular canals to noise-exposed animals 3 weeks after acoustic trauma. The control PCs were generated by transfecting the PCs with an AAV1-GFP viral (null) vector (Figure 6E). The conditioned PCs were transfected with an $A A V 1-H R E-V E G F-A 165$ viral vector (Figure 6E). The $A A V 1-H R E-V E G F-A 165$ viral vector will only allow VEGFA165 to be produced under hypoxic conditions. Two weeks following PC delivery, ELISA was used to test the ability of the $A A V 1-V E G F-A_{165}$ transfected PCs to drive VEGF- $\mathrm{A}_{165}$ expression in the cochlea. No differences were observed in the control PC transplanted and non-PC transplanted cochlea. However, higher production of VEGF-A165 was observed in the conditioned PC transplanted cochlea than in the non-transplanted cochlea or transplanted control PC group (Supplemental Figure S1). To investigate the therapeutic effect of PC transplantation on vascular regeneration, EdU was intraperitoneally injected at $25 \mathrm{mg} / \mathrm{kg}$ body weight to animals of the transplanted and control groups immediately after vector delivery and then subsequently every 2 days until the animals were sacrificed. Endothelium was labeled with lectin-Alexa Fluor 647, with concurrent labeling of PCs for their marker protein, platelet-derived growth factor receptor $\beta$ (Figure $6 \mathrm{G}$ ). These data revealed that transplantation of PCs strongly promotes angiogenesis. A larger population of $\mathrm{EdU}^{+}$cells, including PCs, ECs, and an unknown cell type surrounding vessels, was found in the PC transplanted mouse cochleae (Figure 6, F and G) relative to non-PC transplanted mouse cochleae (Figure 6F). Particularly strong angiogenetic activity was observed in the conditioned PC transplanted cochleae. A significantly increased population of total $\mathrm{EdU}^{+}$PCs was detected in the PC transplanted cochleae compared with the non-PC transplanted cochleae (Figure 6I). Reduced vascular density in the PC transplanted group was significantly attenuated (Figure $6 \mathrm{H}$ ).

Transplantation of Neo-PCs Improves Strial Blood Flow and EP and Attenuates Hearing Loss

In this study, a high-resolution intravital fluorescence microscopy (IVM) was also used to measure vascular function approximately 5 weeks after noise exposure in noiseexposed without PC treatment, noise exposed + control 

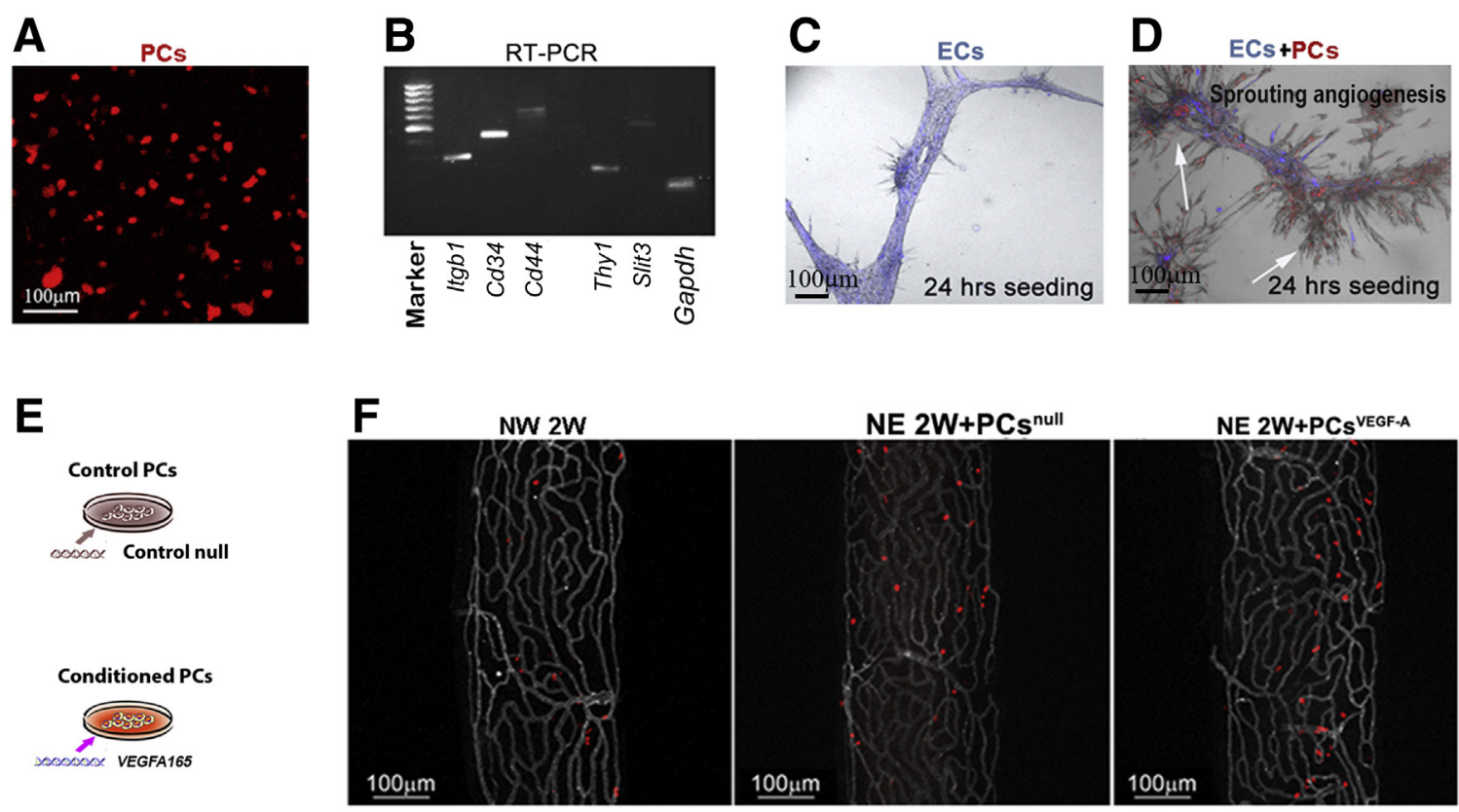

G

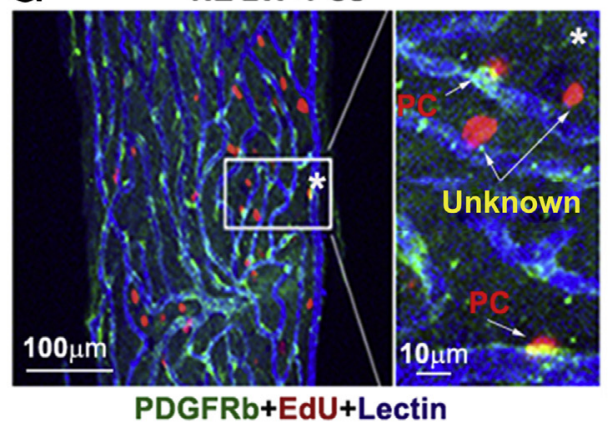

H

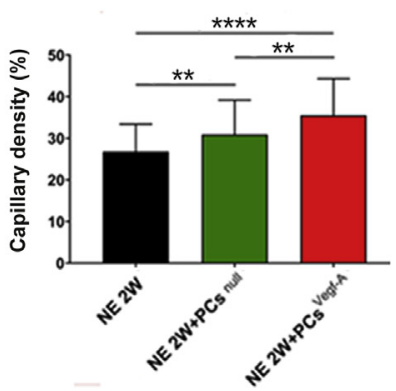

Figure 6 Pericytes $(P C s)$ promote sprouting angiogenesis in an in vitro cell line-based three-dimensional (3D) co-culture model. Transplantation of exogenous PCs attenuates the degenerative damage and promotes strial blood flow. A: PCs derived from neonatal day 10 mouse cochleae (neo-PCs) were generated and tagged with m0range. B: Mesenchymal gene expression in neo-PCs was assessed by PCR. C and D: Images of endothelial cells (ECs) and $\mathrm{ECS}+$ neo-PCs in culture and the angiogenesis at 24 hours. C: Capillary-like tube structures are formed by ECs at 24 hours in 3D matrix gel. D: Co-culture of $\mathrm{ECs}+$ nonconditioned neo-PCs at 24 hours in 3D matrix gel shows that the PCs promote sprouting angiogenesis (white arrows). E: Illustrations of control neoPCs and conditioned neo-PCs. F: 5-Ethynyl-2'-deoxyuridine-positive $\left(\mathrm{EdU}^{+}\right)$cells in stria 5 weeks after noise exposure without PC treatment (left panel), noise exposure + control PC ( $\mathrm{PC}$ null, middle panel), and noise exposure + conditioned neo-PC ( $\mathrm{PC} C^{\mathrm{VEGF}-\mathrm{A}}$ ) treatment 3 weeks after acoustic trauma (right panel). G: Left and right: Low and zoomed-in (asterisk) images show details in EdU ${ }^{+}$cells, capillaries labeled by lectin (blue), and PCs labeled by plateletderived growth factor receptor (PDGFR) $\beta$ (green). $\mathbf{H}$ and $\mathbf{I}$ : Data analysis on EdU ${ }^{+}$cells/vessel area and capillary density in control, nonconditioned, and conditioned neo-PC treated groups $\left[F_{\text {EdU }+/ \text { Vessel Area }}(2,159)=185.57 ; F_{\text {Capillary Density }}(2,159)=16.33\right]$. Data are expressed as means \pm SD $(\mathbf{H}$ and $\mathbf{I}) . n=6$ in each group (H and I). ${ }^{* *} P<0.01,{ }^{* * *} P<0.0001$ (one-way analysis of variance). Scale bars: $100 \mu \mathrm{m}(\mathbf{A}, \mathbf{C}, \mathbf{D}$, and $\mathbf{F}$, and $\mathbf{G}$, left panel); $10 \mu \mathrm{m}(\mathbf{G}$, right panel). VEGFA, vascular endothelial growth factor.

PC transplanted, and noise exposed + conditioned PC groups. Specifically, a vessel window was made at the basal turn of the mouse cochlea. Groups received an i.v. injection of fluorescein isothiocyanate-dextran to label the bloodstream. Fluorescein isothiocyanate fluorescently labeled erythrocytes and plasma were visualized and recorded under IVM using a charge-coupled device video camera. Blood flow rates were calculated from vessel diameter and flow velocity. ${ }^{54}$ Loud sound notably disrupted blood circulation, which caused reduced blood flow and flow disturbances.
Representative images captured under IVM (Figure 7, A-D), show the changed flow pattern in the control and three noise-exposed groups. A disturbed pattern of blood flow is seen in the noise-exposed group (Figure 7B), whereas relatively less disturbance of blood flow was seen in the PC transplanted groups (Figure 7, C and D). Blood velocity calculated for the noise-exposed group was significantly lower than that for noise-exposed animals with PC transplantation. In particular, improved blood circulation was seen in the conditioned PC transplanted group relative 

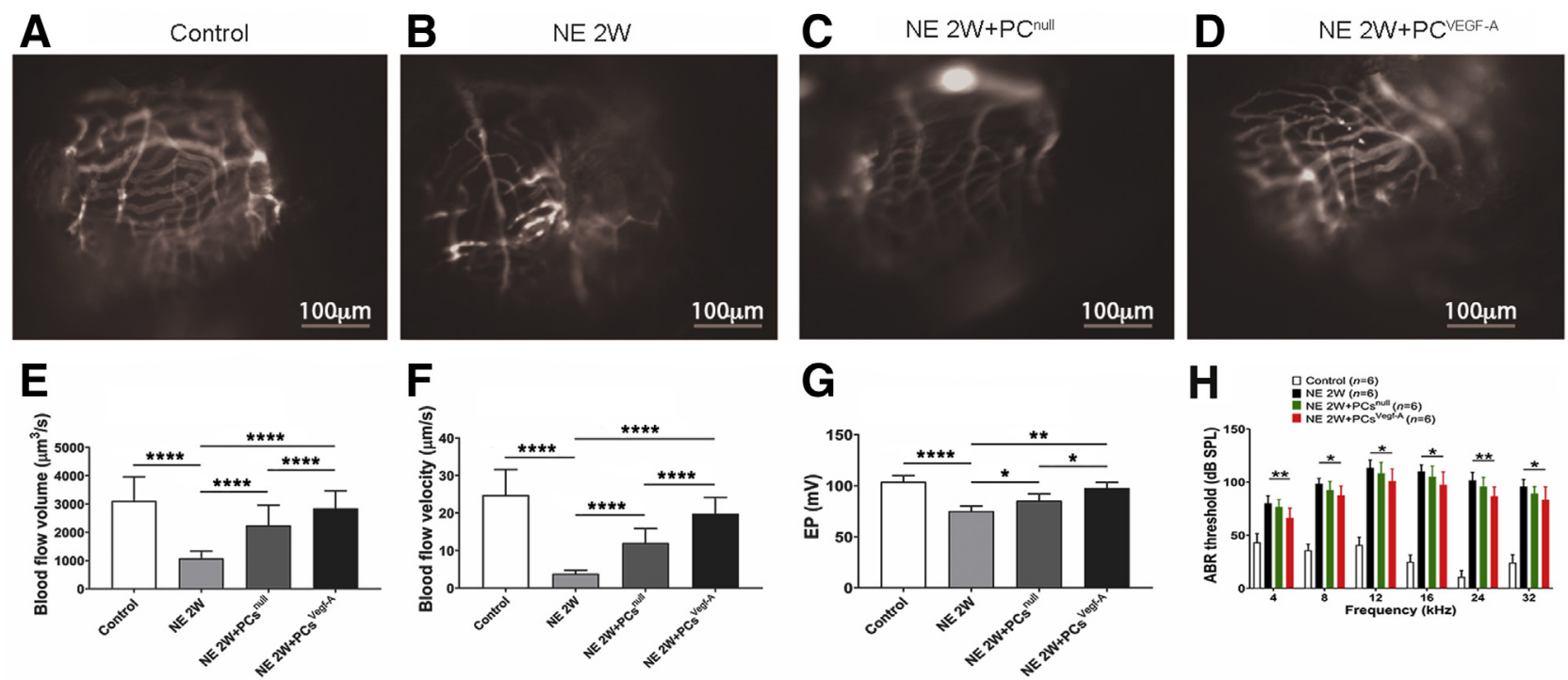

Figure 7 Transplantation of pericytes (PCs) derived from neonatal day 10 mouse cochleae (neo-PCs) improves strial blood flow. Neo-PC treatment markedly improves blood circulation and attenuates endocochlear potential (EP) decline and hearing impairment. A-D: Blood circulation was recorded under highresolution intravital fluorescence microscopy from the control, noise-exposed (NE), NE-control PC (AAV1 ${ }^{\text {null }}$ ), and NE-conditioned PC (AAV1 ${ }^{\mathrm{VEGF}-\mathrm{A}}$ ) groups. E and $\mathbf{F}$ : Blood flow volume $\left(\mu \mathrm{m}^{3} /\right.$ second) and blood flow velocity ( $\mu \mathrm{m} /$ second) were calculated for the control, $\mathrm{NE}, \mathrm{NE}+$ control PC, and $\mathrm{NE}+$ conditioned PC groups. Blood flow rate and volume in the noise-exposed group is lower than that in the PC-treated groups. The conditioned PC-treated group shows increased blood volume and flow rate compared with the control PC treated group $\left[F_{\text {Velocity }}(3,212)=222.535 ; F_{\text {Blood Flow Volume }}(3,212)=102.765\right]$. G: Average EP in the control, NE, NE + control PC, and NE + conditioned PC groups. H: Hearing threshold at different frequencies is significantly elevated 1 month after loud sound exposure. Although hearing sensitivity is not improved in the non-PC transplanted animals, the hearing sensitivity of animals in the $P C$ treated groups is improved. Data are expressed as means \pm SD $(\mathbf{E}, \mathbf{F}$, and $\mathbf{H}) . n=6$ in each group $(\mathbf{E}, \mathbf{F}, \mathbf{H}) ; n=3$ in each group $(\mathbf{G}) .{ }^{*} P<0.05,{ }^{* *} P<0.01$, and ${ }^{* * * * P} P<0.0001$ (one-way analysis of variance). Scale bars $=100 \mu \mathrm{m}(\mathbf{A}-\mathbf{D})$. ABR, auditory brainstem response; SPL, sound pressure level; VEGFA, vascular endothelial growth factor.

to the nonconditioned PC treatment group. Statistically, the blood flow rate and volume in conditioned PC-treated groups were significantly higher relative to the control nonconditioned PC group (Figure 7, E and F). Taken together, the data indicate that PC transplantation significantly improves acoustic trauma-caused blood flow reduction.

The cochlea is a metabolically demanding organ. ${ }^{40}$ Maintenance of a normal blood supply to the cochlea is critical for hearing function, particularly for maintaining the $\mathrm{EP}$, the essential driving force for hair cell transduction. In this study, we demonstrated that restoration of vascular function significantly improves EP and attenuates hearing loss. EP was measured 2 weeks after PC transplantation (5 weeks after noise exposure). Average EP values from control, noise-exposed, control conditional PC transplanted, and conditional PC transplanted groups are shown (Figure $7 \mathrm{G}$ ). The EP in noise-exposed animals was lower (approximately $72.71 \pm 6.1 \mathrm{mV}$ ) than in normal animals (approximately $101 \pm 4.7 \mathrm{mV}$ ). Both control conditioning and conditional PC transplantation significantly ameliorated the decline in the EP, with EPs of $85.98 \pm 5.3$ and $97.75 \pm 5.5 \mathrm{mV}$, respectively. Both groups also showed marked improvement in hearing sensitivity at all measured sound frequencies at 2 weeks after PC transplantation. Hearing threshold measured at low and high frequencies in the control, noise-exposed, control conditional, and conditional PC transplantation groups are shown (Figure $7 \mathrm{H}$ ).

\section{Discussion}

In the present study, a portion of strial PCs are converted to myofibroblast-like cells after loud sound stimulation. The PC transition is strongly associated with increased levels of TGF- $\beta 1$. The strial PC-to myofibroblast-like cell transition causes blood vessel shrinkage with increased deposition of matrix proteins, including collagen type IV and laminin, in the strial vascular basement membrane, leading to capillary atrophy. However, transplantation of young (neo) PCs to the loud sound-damaged cochlea effectively attenuates the strial vascular atrophy. Most interestingly, pretransfection of the PCs with AAVI-HRE-VEGF-A165 strongly ameliorates the stria degeneration compared with transfection with the control AAV1-null. These findings provide strong evidence that loud sound-triggered emergence of myofibroblast-like PCs could be a cause of capillary wall thickening and regression. The damage and degeneration seen in vessels from exposure to loud sound can be halted by transplantation with neo-PCs.

\section{The Strial PC-to-Myofibroblast-Like Cell Transformation Shown as a New Mechanism of Loud Sound-Induced Degeneration of Capillaries}

Strial capillaries in the cochlear lateral wall constitute the blood-labyrinth barrier, a highly specialized tissue densely populated by PCs. PCs, as pluripotent progenitor cells surrounding vessel walls, are vital for vascular integrity, 
angiogenesis, and tissue fibrogenesis. ${ }^{16,17,19}$ They are also extremely vulnerable, such as to acoustic trauma. A PC-tomyofibroblast transition induced by stress is one of the major causes of capillary degeneration in other organs, especially in the kidney. ${ }^{31}$ The PC-to-myofibroblast transition was first reported in the central nervous system during wound formation following a spinal cord injury. ${ }^{27}$ Subsequently, the PC-to-myofibroblast transition has been shown in skin, skeletal muscle, lung, intestine, and kidney. ${ }^{28-30}$

The transition in other organs strongly involves TGF- $\beta 1$ signaling. ${ }^{32-34}$ TGF- $\beta 1$, a pluripotent growth factor that regulates cell proliferation and differentiation, is a major signal in PC-induced tissue fibrogenesis. ${ }^{20,34}$ Blockage of the TGF- $\beta 1$ signaling attenuates the PC-to-myofibroblast transition. Consistent with reports in other organs, the strial PC-tomyofibroblast-like transition in the cochlea also strongly involved TGF- $\beta 1$ signaling. Tgfbl at both the transcript and protein level is highly up-regulated at 1 to 2 weeks after loud sound stimulation (Figure 1). Concurrent with the high production of TGF- $\beta 1$, a PC-to-myofibroblast transition also appears, whereas blockage of the TGF- $\beta 1$ signal attenuates the PC-to-myofibroblast-like transition. The PC-tomyofibroblast-like transition associated with TGF- $\beta 1$ signaling was further confirmed in an in vitro cell line-based model. This cell line model allows us to directly investigate the PC response to TGF- $\beta 1$. The percentage of PC-tomyofibroblast-like transition was found to vary in a dosedependent manner to TGF- $\beta 1$ treatment (Figure 2).

PCs have been identified as the main source of myofibroblasts in progressive fibrotic kidneys after unilateral ureteral obstruction. $^{51,64}$ The PCs transition to myofibroblasts and cause the fibrosis in the tissue. The myofibroblast is a specialized cell type that synthesizes collagen and other extracellular matrix components. ${ }^{16}$ The excessive deposition of extracellular matrix components produced by the myofibroblasts leads to tissue fibrosis and capillary degeneration. ${ }^{28,31,32}$ For example, a study from Goritz et $\mathrm{al}^{27}$ demonstrated a special subtype of PC is the source of scar-forming cells in the injured adult spinal cord. This is consistent with previous reports on other organs. ${ }^{28,32,34}$ In this study, collagen type IV and laminin, the major basement membrane proteins in the strial capillary, ${ }^{60,65}$ were significantly up-regulated at both the transcript and protein level at 2 weeks after loud sound exposure (Figure 2). Increased collagen IV and laminin are particularly found at the sites of transformed PCs. A 3D Matrigel matrix system was used to directly test the functional effect of the transdifferentiated PCs on formation of capillary networks and expression of basement membrane protein. We validated that the transformed PCs stimulated production of collagen type IV and laminin and caused ECs to form thicker branches and less branching. To determine whether the PCto-myofibroblast transition is correlated with strial capillary degeneration, whole mounts of the stria vascularis from NG2DsRedBAC fluorescence PC reporter mice were examined. The fluorescent reporter in the PCs helped identify the phenotype of the observed myofibroblasts. The isolated whole-mounted strial tissue model affords a global view of the non-PC transition and PC-to-myofibroblast transition over the entirety of the strial capillary region. Strial capillary density and diameter in whole mounts of the strial vascularis in the areas of both PC transition and nonPC transition were compared, and a significant difference in vascular diameter in the compared regions is observed (Figure 5). The results reveal new mechanisms of strial capillary degeneration in the ear. In addition to PC transformation caused capillary degeneration, PCs have contractile activity, as reported in an earlier study ${ }^{66}$ and from nonauditory systems in other reports. ${ }^{18,67}$ In particular, the increased $\alpha$-SMA expression in the PCs could be the result of blood flow shut down (nonflow phenomena) by PCtriggered acute contraction of the capillary. In the ear, there is accumulating evidence that noise-induced cochlear hypoxia causes a burst of free radicals, such as nitric oxide, ${ }^{4,68-70}$ and cytokines, such as tumor necrosis factor. ${ }^{71-73}$ These free radicals and inflammatory cytokines, in particular tumor necrosis factor, not only directly cause decrease in blood supply but also act in concert with free radicals to exacerbate PC contractile activity, as has been reported in inner ear ${ }^{74,75}$ and in nonauditory organs. ${ }^{17,76}$ The capillary shrinkage or narrowing (contraction) could be due to PC transformation from $\alpha$-SMA negative to $\alpha$-SMA positive, resulting in deposition of matrix protein to the basement membrane, trigger of vascular contraction at the capillary level, or both.

\section{PC Transplantation for Remodel of Loud Sound-Damaged Strial Capillaries}

Damage to capillaries shuts down blood circulation and jeopardizes regional energy supply. Vascular remodeling and repair are critical for restoration of normal blood circulation. This is particularly important because generation of the EP is so metabolically demanding. ${ }^{40}$ It was earlier demonstrated that loud sound-damaged vessels can be repaired by circulating bone marrow cells signaled through an intrinsic nitric oxide/ stromal cell-derived factor- $1 \alpha$ pathway. ${ }^{1}$ However, in that study, the animals must receive a high dose of radiation to suppress the immune system and curtail immunoreactions, which in itself may induce hearing loss, as has been reported in human studies since the early 1960s. ${ }^{77}$ To avoid such complications, PC transplantation provides a better alternative strategy for the repair of loud sound-induced vascular damage. PCs not only retain their mesenchymal stem cell properties (expression of $C d 44$, Thyl, Itgbl, and Cd34), they have also been shown to play a key role in wound healing, particularly in vascular repair and regeneration. ${ }^{78}$ The PCs have a low immunogenic profile. ${ }^{44}$ Transplantation of purified human PC progenitor cells into mouse heart tissue has been shown to markedly improve repair of infarct and long-term cardiac function without immune rejection. ${ }^{44}$ PCs can activate the angiogenic process by releasing various growth factors, such 
as basic fibroblast growth factor, hepatocyte growth factor, epidermal growth factor, and angiopoietin 1, to induce EC proliferation. ${ }^{42,44}$ Can PCs transplanted into a loud sound-damaged cochlea repair loud sound-damaged vessels and promote cochlear neovascularization? To test this, PCs were isolated from postnatal day $10 \mathrm{C} 57 / 6 \mathrm{~J}$ mice using an established mini-chip method (for details, see Neng et $\mathrm{al}^{49}$ ). The purified PCs were then transfected with an AAV1mediated VEGF-A165 under the control of a hypoxia response enhancer ${ }^{51}$ or control vector (AAV1 null). The timing of stem cell implantation is important for cell fate in vivo. ${ }^{79}$ For optimal results, the neo-PCs were transplanted into the loud sound-damaged cochlea at 3 weeks after acoustic trauma via semicircular canal infusion. The timing of PC transplantation (3 weeks after loud sound stimulation) was selected to bypass time-dependent inflammatory response to traumatic cochlear injury. ${ }^{80-83}$ At 3 weeks, the expression of inflammatory cytokines and reactive free radicals is significantly down-regulated. $^{82,83}$ The transplanted PCs are not as subject to high oxidative stress, necrosis, or apoptosis. Most important, however, hypoxia-inducible factor $1 \alpha$ is significantly up-regulated by the loud sound exposure, ${ }^{45,84}$ and persists for up to 4 weeks after the loud sound stimulation (J.Z, unpublished data). Hypoxia-inducible factor $1 \alpha$ is a potent inducer of VEGF. ${ }^{85}$ High levels of VEGF in the loud sound-damaged cochlea facilitate PC-mediated angiogenesis. A recent study demonstrates that a VEGF-A isoform, VEGF- $\mathrm{A}_{165}$, strongly initiates cochlear angiogenesis in vitro. ${ }^{86}$ To test whether VEGF- $\mathrm{A}_{165}$ promotes PC regeneration, a therapeutic VEGF- $\mathrm{A}_{165}$ viral vector based on AAV serotype 1 was developed, with the AAV1 virus-encoded VEGF- $\mathrm{A}_{165}$ gene under the control of HRE. The VEGF- $A_{165}$ is only produced in a targeted cell under hypoxic conditions (avoiding overexpression of VEGF$A_{165}$ ). Delivery of the AAV1-based VEGF- $A_{165}$ gene vector to loud sound-damaged animals in vivo significantly promotes regeneration of vascular cells. The degree to which PC transplantation promotes structural recovery was determined by assessing vascular cells, including PC and EC proliferation and strial capillary density. The EC proliferation was assessed by nuclear incorporation of EdU in ECs, an indicator the ECs are proliferating. ${ }^{87}$ These results show that the number of ECs proliferating is significantly higher in the PC-transplanted animals than in untransplanted animals. In this study, vascular function was also assessed by measuring blood flow in the lateral wall with an advanced IVM system. Using IVM, it was observed that vascular function (blood flow velocity and volume) is significantly improved by PC transplantation, particularly with $A A V 1-V E G F-A_{165}$ gene transfected PC delivery (Figure 7). Maintenance of normal blood flow is critical for hearing, ${ }^{13,88}$ as normal function of the stria is not only essential for adult outer hair cell survival, ${ }^{89}$ it is also important for maintaining the EP, an essential driving force for hair cell mechanotransduction. ${ }^{90}$ It is not surprising that restoration of failed vascular function attenuates loss in EP and improves hearing sensitivity (Figure 7). Although hearing function significantly reversed, the hearing function improvement is not dramatic. The level of loud sound used in the study is expected to cause both mechanical and metabolic (hypoxic) damage to vascular and nonvascular cells (hair cells) in the cochlea. ${ }^{91}$ Restoration of vascular function would not be expected to restore lost sensory hair cells but it could, with rapid reestablishment of blood supply, prevent further hair cell death, stabilize residual hearing after damage, and potentially accelerate hearing recovery.

In conclusion, cochlear PC function is a double-edged sword. On the one hand, pericyte phenotype conversion leads to capillary regression. On the other hand, healthy pericyte transplantation effectively rehabilitates vascular defects following loud sound-induced strial atrophy. Our new findings indicate that loud sound-triggered emergence of a PC-to-myofibroblast-like cell transition is one cause of capillary wall thickening and regression, whereas transplantation with new fresh pericytes effectively rehabilitates the vascular defects of loud sound-induced strial atrophy. Because sound transduction is metabolically demanding, reduction in blood flow to the ear leads to a shortage of nutrients and oxygen in the tissue, and generates a toxic environment with accumulation of harmful metabolites. To sustain hearing acuity, a healthy cochlear microenvironment must be maintained. The results generated from this study point to potential therapeutic targets for clinical treatment of post-loud sound-induced strial degeneration.

\section{Supplemental Data}

Supplemental material for this article can be found at http://doi.org/10.1016/j.ajpath.2020.05.019.

\section{References}

1. Dai M, Yang Y, Omelchenko I, Nuttall AL, Kachelmeier A, Xiu R, Shi X: Bone marrow cell recruitment mediated by inducible nitric oxide synthase/stromal cell-derived factor-1alpha signaling repairs the acoustically damaged cochlear blood-labyrinth barrier. Am J Pathol 2010, 177:3089-3099

2. Hukee MJ, Duvall AJ 3rd: Cochlear vessel permeability to horseradish peroxidase in the normal and acoustically traumatized chinchilla: a reevaluation. Ann Otol Rhinol Laryngol 1985, 94:297-303

3. Kellerhals B: Acoustic trauma and cochlear microcirculation: an experimental and clinical study on pathogenesis and treatment of inner ear lesions after acute noise exposure. Adv Otorhinolaryngol 1972, 18:91-168

4. Shi X, Nuttall AL: Upregulated iNOS and oxidative damage to the cochlear stria vascularis due to noise stress. Brain Res 2003, 967 : $1-10$

5. Suzuki M, Yamasoba T, Ishibashi T, Miller JM, Kaga K: Effect of noise exposure on blood-labyrinth barrier in guinea pigs. Hear Res 2002, 164:12-18

6. Zhang F, Dai M, Neng L, Zhang JH, Zhi Z, Fridberger A, Shi X: Perivascular macrophage-like melanocyte responsiveness to acoustic trauma-a salient feature of strial barrier associated hearing loss. FASEB J 2013, 27:3730-3740

7. Axelsson A, Dengerink H: The effects of noise on histological measures of the cochlear vasculature and red blood cells: a review. Hear Res 1987, 31:183-191 
8. Axelsson A, Vertes D: Histological Findings in Cochlear Vessels after Noise. New York, NY, Raven Press, 1982. pp. 49-68

9. Hawkins J: Comparative otopathology: aging, noise, and ototoxic drugs. Edited by Otophysiology. Basel, Switzerland: Karger Publishers, 1973. pp. 125-141

10. Shaddock LC, Hamernik RP, Axelsson A: Cochlear vascular and sensory cell changes induced by elevated temperature and noise. Am J Otolaryngol 1984, 5:99-107

11. Yamane H, Nakai Y, Konishi K, Sakamoto H, Matsuda Y, Iguchi H: Strial circulation impairment due to acoustic trauma. Acta Otolaryngol 1991, 111:85-93

12. Shi X: Physiopathology of the cochlear microcirculation. Hear Res 2011, 282:10-24

13. Shi X: Pathophysiology of the cochlear intrastrial fluid-blood barrier (review). Hear Res 2016, 338:52-63

14. Shi X, Han W, Yamamoto H, Tang W, Lin X, Xiu R, Trune DR, Nuttall AL: The cochlear pericytes. Microcirculation 2008, 15: $515-529$

15. Dore-Duffy P, Katychev A, Wang X, Van Buren E: CNS microvascular pericytes exhibit multipotential stem cell activity. J Cereb Blood Flow Metab 2006, 26:613-624

16. Greenhalgh SN, Iredale JP, Henderson NC: Origins of fibrosis: pericytes take centre stage. F1000Prime Rep 2013, 5:37

17. Hall CN, Reynell C, Gesslein B, Hamilton NB, Mishra A, Sutherland BA, O'Farrell FM, Buchan AM, Lauritzen M, Attwell D: Capillary pericytes regulate cerebral blood flow in health and disease. Nature 2014, 508:55-60

18. Peppiatt CM, Howarth C, Mobbs P, Attwell D: Bidirectional control of CNS capillary diameter by pericytes. Nature 2006, 443:700-704

19. Quaegebeur A, Segura I, Carmeliet P: Pericytes: blood-brain barrier safeguards against neurodegeneration? Neuron 2010, 68:321-323

20. Greenhalgh SN, Conroy KP, Henderson NC: Healing scars: targeting pericytes to treat fibrosis. QJM 2015, 108:3-7

21. Greif DM, Eichmann A: Vascular biology: brain vessels squeezed to death. Nature 2014, 508:50-51

22. Liu S, Agalliu D, Yu C, Fisher M: The role of pericytes in blood-brain barrier function and stroke. Curr Pharm Des 2012, 18:3653-3662

23. O'Farrell FM, Attwell D: A role for pericytes in coronary no-reflow. Nat Rev Cardiol 2014, 11:427-432

24. Puro DG: Physiology and pathobiology of the pericyte-containing retinal microvasculature: new developments. Microcirculation 2007, 14:1-10

25. Kim JM, Hong KS, Song WK, Bae D, Hwang IK, Kim JS, Chung HM: Perivascular progenitor cells derived from human embryonic stem cells exhibit functional characteristics of pericytes and improve the retinal vasculature in a rodent model of diabetic retinopathy. Stem Cells Transl Med 2016, 5:1268-1276

26. Pfister F, Feng Y, vom Hagen F, Hoffmann S, Molema G, Hillebrands JL, Shani M, Deutsch U, Hammes HP: Pericyte migration: a novel mechanism of pericyte loss in experimental diabetic retinopathy. Diabetes 2008, 57:2495-2502

27. Goritz C, Dias DO, Tomilin N, Barbacid M, Shupliakov O, Frisen J: A pericyte origin of spinal cord scar tissue. Science 2011, 333: $238-242$

28. Ren S, Duffield JS: Pericytes in kidney fibrosis. Curr Opin Nephrol Hypertens 2013, 22:471-480

29. Rosas IO, Kottmann RM, Sime PJ: New light is shed on the enigmatic origin of the lung myofibroblast. Am J Respir Crit Care Med 2013, 188:765-766

30. Steinhauser ML, Lee RT: Pericyte progenitors at the crossroads between fibrosis and regeneration. Circ Res 2013, 112:230-232

31. Pan SY, Chang YT, Lin SL: Microvascular pericytes in healthy and diseased kidneys. Int J Nephrol Renovasc Dis 2014, 7:39-48

32. Rodriguez A, Friman T, Kowanetz M, van Wieringen $T$, Gustafsson R, Sundberg C: Phenotypical differences in connective tissue cells emerging from microvascular pericytes in response to overexpression of PDGF-B and TGF-betal in normal skin in vivo. Am J Pathol 2013, 182:2132-2146
33. Ren S, Johnson BG, Kida Y, Ip C, Davidson KC, Lin SL, Kobayashi A, Lang RA, Hadjantonakis AK, Moon RT, Duffield JS: LRP-6 is a coreceptor for multiple fibrogenic signaling pathways in pericytes and myofibroblasts that are inhibited by DKK-1. Proc Natl Acad Sci U S A 2013, 110:1440-1445

34. Wu CF, Chiang WC, Lai CF, Chang FC, Chen YT, Chou YH, Wu TH, Linn GR, Ling $\mathrm{H}, \mathrm{Wu}$ KD, Tsai TJ, Chen YM, Duffield JS, Lin SL: Transforming growth factor beta-1 stimulates profibrotic epithelial signaling to activate pericyte-myofibroblast transition in obstructive kidney fibrosis. Am J Pathol 2013, 182: $118-131$

35. Vallee A, Lecarpentier Y: TGF-beta in fibrosis by acting as a conductor for contractile properties of myofibroblasts. Cell Biosci 2019, 9:98

36. Lodyga M, Hinz B: TGF-beta1 - a truly transforming growth factor in fibrosis and immunity. Semin Cell Dev Biol 2019, 101:123-139

37. Gratton MA, Schmiedt RA, Schulte BA: Age-related decreases in endocochlear potential are associated with vascular abnormalities in the stria vascularis. Hear Res 1996, 102:181-190

38. Ohlemiller KK, Rice ME, Gagnon PM: Strial microvascular pathology and age-associated endocochlear potential decline in NOD congenic mice. Hear Res 2008, 244:85-97

39. Salt AN, Melichar I, Thalmann R: Mechanisms of endocochlear potential generation by stria vascularis. Laryngoscope 1987, 97: 984-991

40. Wangemann P: Cochlear blood flow regulation. Adv Otorhinolaryngol 2002, 59:51-57

41. Miller JM, Brown JN, Schacht J: 8-Iso-prostaglandin F(2alpha), a product of noise exposure, reduces inner ear blood flow. Audiol Neurootol 2003, 8:207-221

42. Chen CW, Okada M, Proto JD, Gao X, Sekiya N, Beckman SA, Corselli M, Crisan M, Saparov A, Tobita K, Peault B, Huard J: Human pericytes for ischemic heart repair. Stem Cells 2013, 31: 305-316

43. Kelly-Goss MR, Sweat RS, Stapor PC, Peirce SM, Murfee WL: Targeting pericytes for angiogenic therapies. Microcirculation 2014, 21:345-357

44. Katare R, Riu F, Mitchell K, Gubernator M, Campagnolo P, Cui Y, Fortunato O, Avolio E, Cesselli D, Beltrami AP, Angelini G, Emanueli C, Madeddu P: Transplantation of human pericyte progenitor cells improves the repair of infarcted heart through activation of an angiogenic program involving micro-RNA-132. Circ Res 2011, 109:894-906

45. Shi X: Cochlear pericyte responses to acoustic trauma and the involvement of hypoxia-inducible factor-1alpha and vascular endothelial growth factor. Am J Pathol 2009, 174:1692-1704

46. Gao L, Hu Y, Tian Y, Fan Z, Wang K, Li H, Zhou Q, Zeng G, Hu X, Yu L, Zhou S, Tong X, Huang H, Chen H, Liu Q, Liu W, Zhang G, Zeng M, Zhou G, He Q, Ji H, Chen L: Lung cancer deficient in the tumor suppressor GATA4 is sensitive to TGFBR1 inhibition. Nat Commun 2019, 10:1665

47. Higashiyama H, Yoshimoto D, Kaise T, Matsubara S, Fujiwara M, Kikkawa H, Asano S, Kinoshita M: Inhibition of activin receptor-like kinase 5 attenuates bleomycin-induced pulmonary fibrosis. Exp Mol Pathol 2007, 83:39-46

48. Yang Y, Dai M, Wilson TM, Omelchenko I, Klimek JE, Wilmarth PA, David LL, Nuttall AL, Gillespie PG, Shi X: Na+/K+ATPase alpha1 identified as an abundant protein in the bloodlabyrinth barrier that plays an essential role in the barrier integrity. PLoS One 2011, 6:e16547

49. Neng L, Zhang W, Hassan A, Zemla M, Kachelmeier A, Fridberger A, Auer M, Shi X: Isolation and culture of endothelial cells, pericytes and perivascular resident macrophage-like melanocytes from the young mouse ear. Nat Protoc 2013, 8:709-720

50. Neng L, Zhang J, Yang J, Zhang F, Lopez IA, Dong M, Shi X: Structural changes in the strial blood-labyrinth barrier of aged C57BL/6 mice. Cell Tissue Res 2015, 361:685-696 
51. Humphreys BD, Lin SL, Kobayashi A, Hudson TE, Nowlin BT, Bonventre JV, Valerius MT, McMahon AP, Duffield JS: Fate tracing reveals the pericyte and not epithelial origin of myofibroblasts in kidney fibrosis. Am J Pathol 2010, 176:85-97

52. Hanna G, Fontanella A, Palmer G, Shan S, Radiloff DR, Zhao Y, Irwin D, Hamilton $\mathrm{K}$, Boico A, Piantadosi CA, Blueschke G, Dewhirst M, McMahon T, Schroeder T: Automated measurement of blood flow velocity and direction and hemoglobin oxygen saturation in the rat lung using intravital microscopy. Am J Physiol Lung Cell Mol Physiol 2013, 304:L86-L91

53. Narciso MG, Nasimuzzaman M: Purification of platelets from mouse blood. J Vis Exp 2019, 147:e59803

54. Shi X, Zhang F, Urdang Z, Dai M, Neng L, Zhang J, Chen S, Ramamoorthy S, Nuttall AL: Thin and open vessel windows for intravital fluorescence imaging of murine cochlear blood flow. Hear Res 2014, 313:38-46

55. Blueschke G, Hanna G, Fontanella AN, Palmer GM, Boico A, Min H, Dewhirst MW, Irwin DC, Zhao Y, Schroeder T: Automated measurement of microcirculatory blood flow velocity in pulmonary metastases of rats. J Vis Exp 2014, 93:e51630

56. Zhang W, Dai M, Fridberger A, Hassan A, Degagne J, Neng L, Zhang F, He W, Ren T, Trune D, Auer M, Shi X: Perivascularresident macrophage-like melanocytes in the inner ear are essential for the integrity of the intrastrial fluid-blood barrier. Proc Natl Acad Sci U S A 2012, 109:10388-10393

57. Shepro D, Morel N: Pericyte physiology. FASEB J 1993, 7: $1031-1038$

58. Leask A: Towards an anti-fibrotic therapy for scleroderma: targeting myofibroblast differentiation and recruitment. Fibrogenesis Tissue Repair 2010, 3:8

59. Ho YY, Lagares D, Tager AM, Kapoor M: Fibrosis-a lethal component of systemic sclerosis. Nat Rev Rheumatol 2014, 10:390-402

60. Gratton MA, Meehan DT, Smyth BJ, Cosgrove D: Strial marginal cells play a role in basement membrane homeostasis: in vitro and in vivo evidence. Hear Res 2002, 163:27-36

61. Ribatti D, Nico B, Crivellato E: The role of pericytes in angiogenesis. Int J Dev Biol 2011, 55:261-268

62. Gokcinar-Yagci B, Uckan-Cetinkaya D, Celebi-Saltik B: Pericytes: properties, functions and applications in tissue engineering. Stem Cell Rev 2015, 11:549-559

63. Gerhardt H, Betsholtz C: Endothelial-pericyte interactions in angiogenesis. Cell Tissue Res 2003, 314:15-23

64. Lin SL, Kisseleva T, Brenner DA, Duffield JS: Pericytes and perivascular fibroblasts are the primary source of collagen-producing cells in obstructive fibrosis of the kidney. Am J Pathol 2008, 173:1617-1627

65. Cosgrove D, Samuelson G, Pinnt J: Immunohistochemical localization of basement membrane collagens and associated proteins in the murine cochlea. Hear Res 1996, 97:54-65

66. Dai M, Nuttall A, Yang Y, Shi X: Visualization and contractile activity of cochlear pericytes in the capillaries of the spiral ligament. Hear Res 2009, 254:100-107

67. O'Farrell FM, Mastitskaya S, Hammond-Haley M, Freitas F, Wah WR, Attwell D: Capillary pericytes mediate coronary no-reflow after myocardial ischaemia. Elife 2017, 6:e29280

68. Han WJ, Shi XR, Nuttall A: Distribution and change of peroxynitrite in the guinea pig cochlea following noise exposure. Biomed Rep 2018, 9:135-141

69. Chen GD, Daszynski DM, Ding D, Jiang H, Woolman T, Blessing K, Kador PF, Salvi R: Novel oral multifunctional antioxidant prevents noiseinduced hearing loss and hair cell loss. Hear Res 2020, 388:107880

70. Fetoni AR, De Bartolo P, Eramo SL, Rolesi R, Paciello F, Bergamini C, Fato R, Paludetti G, Petrosini L, Troiani D: Noiseinduced hearing loss (NIHL) as a target of oxidative stress-mediated damage: cochlear and cortical responses after an increase in antioxidant defense. J Neurosci 2013, 33:4011-4023
71. Landegger LD, Vasilijic S, Fujita T, Soares VY, Seist R, Xu L, Stankovic KM: Cytokine levels in inner ear fluid of young and aged mice as molecular biomarkers of noise-induced hearing loss. Front Neurol 2019, 10:977

72. Dhukhwa A, Bhatta P, Sheth S, Korrapati K, Tieu C, Mamillapalli C, Ramkumar V, Mukherjea D: Targeting inflammatory processes mediated by TRPVI and TNF-alpha for treating noise-induced hearing loss. Front Cell Neurosci 2019, 13:444

73. Rybak LP, Dhukhwa A, Mukherjea D, Ramkumar V: Local drug delivery for prevention of hearing loss. Front Cell Neurosci 2019, 13:300

74. Arpornchayanon W, Canis M, Ihler F, Settevendemie C, Strieth S: TNF-alpha inhibition using etanercept prevents noise-induced hearing loss by improvement of cochlear blood flow in vivo. Int J Audiol 2013, 52:545-552

75. Bertlich M, Ihler F, Weiss BG, Freytag S, Strupp M, Canis M: Cochlear pericytes are capable of reversibly decreasing capillary diameter in vivo after tumor necrosis factor exposure. Otol Neurotol 2017, 38:e545-e550

76. Yemisci M, Gursoy-Ozdemir Y, Vural A, Can A, Topalkara K, Dalkara T: Pericyte contraction induced by oxidative-nitrative stress impairs capillary reflow despite successful opening of an occluded cerebral artery. Nat Med 2009, 15:1031-1037

77. Borsanyi SJ, Blanchard CL: Ionizing radiation and the ear. JAMA 1962, 181:958-961

78. Mills SJ, Cowin AJ, Kaur P: Pericytes, mesenchymal stem cells and the wound healing process. Cells 2013, 2:621-634

79. Chen Y, Teng X, Chen W, Yang J, Yang Z, Yu Y, Shen Z: Timing of transplantation of autologous bone marrow derived mesenchymal stem cells for treating myocardial infarction. Sci China Life Sci 2014, 57: $195-200$

80. Adams JC, Seed B, Lu N, Landry A, Xavier RJ: Selective activation of nuclear factor kappa B in the cochlea by sensory and inflammatory stress. Neuroscience 2009, 160:530-539

81. Hirose K, Discolo CM, Keasler J, Ransohoff R: Mononuclear phagocytes migrate into the murine cochlea after acoustic trauma. J Comp Neurol 2005, 489:180-194

82. Le Prell CG, Yamashita D, Minami SB, Yamasoba T, Miller JM: Mechanisms of noise-induced hearing loss indicate multiple methods of prevention. Hear Res 2007, 226:22-43

83. Yamashita D, Jiang HY, Schacht J, Miller JM: Delayed production of free radicals following noise exposure. Brain Res 2004, 1019:201-209

84. Chung JW, Kang HH, Shin JE, Kim JU: Accumulation of hypoxiainducible factor-1alpha in mouse inner ear by noise stimulation. Neuroreport 2004, 15:2353-2356

85. Kimura H, Esumi H: Reciprocal regulation between nitric oxide and vascular endothelial growth factor in angiogenesis. Acta Biochim Pol 2003, 50:49-59

86. Wang X, Zhang J, Li G, Sai N, Han J, Hou Z, Kachelmeier A, Shi X: Vascular regeneration in adult mouse cochlea stimulated by VEGFA165 and driven by NG2-derived cells ex vivo. Hear Res 2019, 377:179-188

87. Kempermann G, Neuroscience: What the bomb said about the brain Science 2013, 340:1180-1181

88. Nuttall AL: Techniques for the observation and measurement of red blood cell velocity in vessels of the guinea pig cochlea. Hear Res 1987, 27:111-119

89. Liu H, Li Y, Chen L, Zhang Q, Pan N, Nichols DH, Zhang WJ, Fritzsch B, He DZ: Organ of corti and stria vascularis: is there an interdependence for survival? PLoS One 2016, 11:e0168953

90. Hibino H, Nin F, Tsuzuki C, Kurachi Y: How is the highly positive endocochlear potential formed? the specific architecture of the stria vascularis and the roles of the ion-transport apparatus. Pflugers Arch 2010, 459:521-533

91. Han W, Shi X, Nuttall AL: AIF and endoG translocation in noise exposure induced hair cell death. Hear Res 2006, 211:85-95 